\section{$\checkmark$ Research Square}

Preprints are preliminary reports that have not undergone peer review.

They should not be considered conclusive, used to inform clinical practice, or referenced by the media as validated information.

\title{
From Waste to Reuse: Manufacture of Ecological Composites Based on Biopolyethylene/Wood Powder with PE-g-MA and Macaíba oil
}

\section{Fabiano Santana da Silva}

Universidade Federal de Campina Grande

Carlos Bruno Barreto Luna

Universidade Federal de Campina Grande

D D Siqueira ( $\boldsymbol{\nabla}$ danilodinizsiqueira@gmail.com )

Universidade Federal de Campina Grande https://orcid.org/0000-0002-3533-513X

\section{Eduardo Ferreira}

Universidade Federal de Campina Grande

Edcleide Maria Araujo

Universidade Federal de Campina Grande

\section{Research Article}

Keywords: composites, wood powder, compatibilizer, macaíba oil

Posted Date: March 17th, 2021

DOl: https://doi.org/10.21203/rs.3.rs-306125/v1

License: (c) (i) This work is licensed under a Creative Commons Attribution 4.0 International License.

Read Full License

Version of Record: A version of this preprint was published at Journal of Polymers and the Environment on August 9th, 2021. See the published version at https://doi.org/10.1007/s10924-021-02256-6. 


\section{Abstract}

This work aimed to investigate the biopolyethylene (BioPE)/wood powder (WP) composites compatibilized with polyethylene-grafted maleic anhydride (PE-g-MA), using macaíba oil (OM) as a processing aid. The composites were prepared, initially, in an internal mixer and, later, the crushed flakes were molded by injection. Mechanical properties (impact, tensile, flexural and Shore D hardness), heat deflection temperature (HDT), Vicat softening temperature, differential scanning calorimetry (DSC), thermogravimetry (TG), water absorption, torque rheometry and scanning electron microscopy (SEM) were evaluated. The addition of $30 \%$ wood powder to the BioPE matrix increased the elastic modulus (tensile and flexural), Shore D hardness and heat deflection temperature (HDT), compared to neat BioPE. These properties were improved when $10 \%$ of the PE-g-MA compatibilizer was added, compared to neat BioPE and the non-compatibilized composite. There was a significant reduction in the torque of the composites with the addition of macaíba oil, indicating that it improved the processability. In addition, the incorporation of macaíba oil into the composites helped to reduce water absorption, as well as to increase impact strength. SEM micrographs illustrated a greater degree of interfacial adhesion when PEg-MA and macaiba oil were added.

\section{Introduction}

The plastic industry is one of the sectors of the economy that has developed the most in recent years, generating a large number of products derived from conventional thermoplastics [1]. One of the major problems in the use of conventional plastic materials is the environmental impact caused by their disposal [2]. In recent years, there has been an increasing mobilization for sustainable development, with materials that are less aggressive to natural ecosystems [3-5]. The development of polymeric composites reinforced with natural fibers has received great prominence as an alternative technology for the processing of new materials that provide a lower environmental impact, associated with low density and interesting mechanical properties [6-8].

Natural fibers are commonly used in the production of polymeric composites, as they have advantages such as good availability, biodegradability, low cost, good thermal and mechanical properties, renewable, non-toxic and can be easily modified by chemical agents $[9,10]$. Currently, there is great academic and industrial interest in the preparation of composites reinforced with jute fibers, sisal, cotton, macaíba, linen, palm fiber, coconut fiber, curauá and wood powder, using biodegradable polymers and green polymers [11-13]. These fibers are widely used to reinforce polyethylene (PE) and polypropylene (PP), aiming at the manufacture of materials for applications in the automotive and aerospace industries $[14,15]$.

Biopolyethylene (BioPE) produced from ethanol derived from sugar cane, although not biodegradable, maintains the balance of carbon dioxide $\left(\mathrm{CO}_{2}\right)$ in nature [16]. In addition to being an ecological material, BioPE has the same mechanical and processing properties as the resin made from fossil sources [17]. For this reason, the development of composites with BioPE polymeric matrix is of great importance, due to the potential for technological application and the reduction of environmental impacts [18]. There are 
works in the literature on polyethylene composites reinforced with jute [19, 20], curauá [21], sisal [22, 23], coconut fiber [24, 25], cotton [26], rice husk [27] and wood powder [28, 29], suggesting good mechanical properties.

Castro et al. [30] developed biopolyethylene composites with curauá fibers, using castor and canola oils, as processing aids. When oil was added to the biopolyethylene/curauá fiber composite, it increased the mobility of the polymer chains, decreasing the viscosity of the system and improving processability. In general, the results indicated that the incorporation of oils, particularly castor oil, favored better mechanical properties compared to the composite without oil, indicating the potential of the oil as a compatibilizer.

The use of natural fibers as a reinforcement in composites with biopolyethylene has a great potential to replace synthetic fibers, which will have an impact both in reducing the dependence on materials from non-renewable sources, as well as with regard to environmental and economic aspects [31, 32]. At the same time, there is the possibility of reusing natural fillers, such as wood powder, which is widely discarded by the wood industry. Wood powder residues are sources of environmental pollution and waste of raw material with good properties, with ample potential for reuse in mixtures with polymers [33, 34]. In view of this, both the economic aspects and the environmental pollution are justifications for the research directed with the reuse of wood powder, aiming at the development of composites with good mechanical and thermomechanical properties. The problem associated with the development of composites with high natural filler content is the difficulty during processing, since it increases viscosity. The high viscosity makes it difficult to process the composites, because it is necessary to submit the material between narrow channels in short times, such as extruder and injector. Therefore, aiming at higher productivity with minimum disengage of the equipment, as well as to reduce energy consumption, it is necessary to reduce the composite viscosity. Consequently, it is relevant to investigate processing aid from natural sources, considering that it can improve the composite processing.

The objective of this work was to develop composites of biopolyethylene (BioPE) with wood powder residues, using polyethylene-grafted maleic anhydride (PE-g-MA) as a compatibilizing agent and macaíba oil (OM) as a processing aid.

\section{Materials And Methods}

\subsection{Materials}

- Green high density polyethylene, biopolyethylene (BioPE), sold under the code SHC7260® and melt flow index (MFI) of $7.2 \mathrm{~g} / 10 \mathrm{~min}\left(190^{\circ} \mathrm{C} / 2.16 \mathrm{~kg}\right)$, produced from sugar cane and supplied in the form of pellets by Braskem.

- Angelim wood powder $(420 \mu \mathrm{m})$, with scientific name Dinizia excelsa Ducke, from the wood industry, based in the city of Campina Grande/PB, Brazil. 
- Polyethylene-grafted maleic anhydride (PE-g-MA) was used as a compatibilizing agent, marketed under code $3029 \AA$, with 1.5 to $1.7 \%$ maleic anhydride (MA), supplied in the form of pellets by Addivant. Density of $0.95 \mathrm{~g} / \mathrm{cm}^{3}$ and $\mathrm{MFI}=4.0 \mathrm{~g} / 10 \mathrm{~min}\left(190^{\circ} \mathrm{C} / 2.16 \mathrm{~kg}\right)$.

\subsection{Methods}

\subsubsection{Obtaining Macaíba Oil}

The procedure for extracting macaiba oil was adopted in the literature [35]. For the assembly of the extractor, a heating blanket with a balloon support $(1 \mathrm{~L})$ was used, with the Soxhlet $(700 \mathrm{~mL})$ and the condenser, respectively. Coupled to the system, a coil was installed to cool the water, helping the condensation process. Before starting the extraction process, the filter paper cartridge was weighed on an analytical balance, the mass being determined. After assembling the cartridge with $70 \mathrm{~g}$ of sample, a new weighing was performed to obtain the mass of the cartridge plus the sample. $1 \mathrm{~L}$ of hexane was added to the flask and after coupling to the system, the time-controlled extraction process began. During the extraction, an attempt was made to maintain the flow of hexane in the extractor and with the aid of a thermometer, the internal temperature of the soxhlet was monitored, which varied uniformly between $65^{\circ} \mathrm{C}$ and $70^{\circ} \mathrm{C}$.

\subsubsection{Composites Processing and Injection Molding}

Table 1 illustrates the mass proportions (\%) of the compositions that were used in the development of the composites.

Table 1. Compositions of composites with mass proportions (\%).

\begin{tabular}{|lllll|}
\hline Samples & $\begin{array}{l}\text { BioPE } \\
\text { (\% by weight) }\end{array}$ & $\begin{array}{l}\text { WP } \\
\text { (\% by weight) }\end{array}$ & $\begin{array}{l}\text { PE-g-MA } \\
\text { (\% by weight) }\end{array}$ & $\begin{array}{l}\text { Macaíba Oil } \\
\text { (\% phr) }\end{array}$ \\
\hline BioPE & 100 & - & - & - \\
\hline BioPE/WP & 70 & 30 & - & - \\
\hline BioPE/WP/oil & 70 & 30 & - & 10 \\
\hline BioPE/WP/PE-g-MA & 60 & 30 & 10 & - \\
\hline BioPE/WP/PE-g-MA/oil & 60 & 30 & 10 & 10 \\
\hline
\end{tabular}

The compatibilizer PE-g-MA and the wood powder were dried in a vacuum oven for 24 hours, at a temperature of $60^{\circ} \mathrm{C}$. The composites were dry mixed and subsequently processed in an internal Haake Rheomix 3000 mixer from Thermo Scientific $\left(310 \mathrm{~cm}^{3}\right.$ capacity), with roller type rotors, at $180^{\circ} \mathrm{C}$, rotor rotation speed of $60 \mathrm{rpm}$, under air atmosphere for $10 \mathrm{~min}$. Biopolethylene (BioPE) was processed under the same conditions as composites. Subsequently, the processed material was ground in a knife mill. 
The BioPE and the composites were injection molded, in an Arburg injection molding machine, Model Allrounder 207C Golden Edition, to obtain impact, tensile, flexion and HDT specimens, according to the ASTM D256, ASTM D638, ASTM D790 and ASTM standards D648, respectively. The molding conditions of the specimens are shown in Table 2.

Table 2. Injection molding conditions of specimens.

\begin{tabular}{|ll|}
\hline Parameters & Conditions \\
\hline Injection pressure (bar) & 1000 \\
\hline Temperature profile $\left({ }^{\circ} \mathrm{C}\right)$ & $170,170,170,170,170$ \\
\hline Mold Temperature $\left({ }^{\circ} \mathrm{C}\right)$ & 20 \\
\hline Cooling time inside the mold $(\mathrm{s})$ & 25 \\
\hline Discharge pressure (bar) & 500 \\
\hline
\end{tabular}

\subsubsection{Materials Characterization}

Rheological curves were obtained by a Haake PolyLab QC da Thermo Scientific mixer with roller-type rotors at $170^{\circ} \mathrm{C}$ and $60 \mathrm{rpm}$ rotor speed inside an air atmosphere for $10 \mathrm{~min}$. The total mass (Mt) processed in the mixer was measured according to Equation (1):

$M t=0.7 \times D \times V_{n}$

where, $D=$ material density to be processed; $0.7=$ factor corresponding to $70 \%$ of the occupied volume inside the camera; $\mathrm{Vn}=$ free volume of mixing chamber $\left(69 \mathrm{~cm}^{3}\right)$.

Izod impact strength test was performed in notched specimens, according to ASTM D256, in a Ceast model Resil $5.5 \mathrm{~J}$, operating with a hammer of $2.75 \mathrm{~J}$, at room temperature $\left(\sim 23^{\circ} \mathrm{C}\right)$. Results were analyzed with an average of seven specimens.

Tensile test was performed with injected specimens, according to ASTM D638, using an universal test machine EMIC DL 2000, with a rate of $50 \mathrm{~mm} / \mathrm{min}$ and load cell of $20 \mathrm{kN}$, at room temperature $\left(\sim 23^{\circ} \mathrm{C}\right)$. Results were analyzed with an average of seven specimens.

The flexural test was performed on a universal testing machine of the EMIC DL 2000 brand, according to the ASTM D790 standard, operating in flexion mode at three points, with a speed of $1.6 \mathrm{~mm} / \mathrm{min}$, separation between the supports of $40 \mathrm{~mm}$ and $20 \mathrm{kN}$ load cell. The results were analyzed with an average of seven specimens.

The penetration resistance was determined according to the ASTM D2240 standard, on a Shore "D" durometer, with a $50 \mathrm{~N}$ load controlled by calibrated springs by means of standardized indenters. The results were analyzed with an average of seven penetrations. 
Heat deflection temperature (HDT) experiment was measured according to ASTM D648 in a Ceast model HDT 6 VICAT, with a voltage of $455 \mathrm{kPa}$ and a heating rate of $120^{\circ} \mathrm{C} / \mathrm{h}$ (method A). The temperature was determined after the sample deflecting $0.25 \mathrm{~mm}$. Results were analyzed with an average of three specimens.

Differential Scanning Calorimetry (DSC) analysis was performed in a DSC-Q20 from TA Instruments. The scans were computed from 30 to $200^{\circ} \mathrm{C}$, under a heating rate of $10^{\circ} \mathrm{C} / \mathrm{min}$, gas flow rate of $50 \mathrm{~mL} / \mathrm{min}$, in nitrogen atmosphere, samples with approximately $6 \mathrm{mg}$ were tested.

The thermogravimetry (TG) analyzes were obtained in a simultaneous TG/DSC equipment from TA Instruments SDT Q600, employing about $5 \mathrm{mg}$ of sample, with heating rate of $10^{\circ} \mathrm{C} / \mathrm{min}$ and gas flow rate of $100 \mathrm{~mL} / \mathrm{min}$, starting at a temperature of 30 to $510^{\circ} \mathrm{C}$, under a nitrogen atmosphere.

The water absorption test was based on the procedure suggested in ASTM D570. The specimens were conditioned in the oven under vacuum, for $24 \mathrm{~h}$ at $60^{\circ} \mathrm{C}$. After this period, they were immediately weighed on a precision scale, and the mass was obtained before immersion (M0). Then, the specimens were submerged in water at room temperature $\left(\sim 23^{\circ} \mathrm{C}\right)$, so that the samples were completely immersed, obtaining the mass after immersion (Mf). At predetermined time intervals, the specimens were removed from the water (dried with a cloth), weighed on a precision scale and, again, placed in the bath. The percentage of water absorption was calculated from Equation 2.

$$
\text { Water absorption }(\%)=\frac{M_{f}-M_{0}}{M_{0}} \times 100 \%
$$

Scanning Electronic Microscope (SEM) analysis was obtained with a VEGAN 3 TESCAN device with a 30 $\mathrm{kV}$ voltage and under high vacuum conditions. The fracture surfaces of impact samples were analyzed. The surfaces were coated with a gold layer.

\subsubsection{Statistical Hypothesis Testing}

The statistical hypothesis testing is a procedure that allows a decision to be made between two or more hypotheses (null hypothesis $\mathrm{H}_{0}$ or alternative hypothesis $\mathrm{H}$ ), using the observed data from a given experiment. Student's t test was applied to compare impact strength, tensile strength, flexural modulus, Shore D hardness and heat deflection temperature (HDT). The criterion adopted for comparative effect was the impact of adding macaíba oil to the properties. Therefore, similar composites BioPE/WP; BioPE/WP/oil and BioPE/WP/PE-g-MA; BioPE/WP/PE-g-MA/oil were evaluated. Table 3 shows the conditions adopted for a $95 \%$ confidence level.

Table 3. Conditions tested for Student's t test. 


\begin{tabular}{|c|c|c|}
\hline Property & Hypothesis & $t_{\text {table }}{ }^{*}$ \\
\hline & $\mathrm{H}_{0}$ : There is no significant difference. & \\
\hline \multirow[t]{2}{*}{ Impact strength $\left(a_{0}\right)$} & $\mathrm{H}$ : There is a significant difference. & 2.446 \\
\hline & $\mathrm{H}_{0}$ : There is no significant difference. & \\
\hline \multirow[t]{2}{*}{ Tensile strength $\left(a_{0}\right)$} & $\mathrm{H}$ : There is a significant difference. & -2.446 \\
\hline & $\mathrm{H}_{0}$ : There is no significant difference. & \\
\hline \multirow[t]{2}{*}{ Elastic modulus $\left(\mathrm{a}_{0}\right)$} & $\mathrm{H}$ : There is a significant difference. & -2.446 \\
\hline & $\mathrm{H}_{0}$ : There is no significant difference. & \\
\hline \multirow[t]{2}{*}{ Flexural modulus $\left(a_{0}\right)$} & $\mathrm{H}$ : There is a significant difference. & -2.446 \\
\hline & $\mathrm{H}_{0}$ : There is no significant difference. & \\
\hline \multirow[t]{2}{*}{ Shore D hardness $\left(a_{0}\right)$} & $\mathrm{H}$ : There is a significant difference. & -2.446 \\
\hline & $\mathrm{H}_{0}$ : There is no significant difference. & \\
\hline $\operatorname{HDT}\left(a_{0}\right)$ & $\mathrm{H}$ : There is a significant difference. & -3.182 \\
\hline
\end{tabular}

* From the literature [82].

\section{Results And Discussion}

\subsection{Torque Rheometry}

Torque rheometry is a technique used to evaluate the reactivity and processability of composites [36]. Figure 1 shows the torque versus time curves for neat BioPE and composites with and without macaíba oil. A significant increase in torque is observed in $1 \mathrm{~min}$ of processing, due to the solid material in the mixing chamber and, therefore, greater mechanical work to rotate the rotor. Composites have a higher intense peak torque compared to neat BioPE. Such behavior is due to the process of distribution and dispersion of wood flour particles, since they are harder. Apparently, the presence of macaiba oil did not significantly influence processing start of processing, possibly due to the high content of wood flour. After melting and mixing, the torque for all materials decreases and stabilizes, suggesting a homogeneous mixture. It appears that after 3 min of the process, the torque of the BioPE is constant, with a value around $1.8 \mathrm{~N}$.m. This behavior indicates viscosity stability for the process conditions used, i.e., a speed of $60 \mathrm{rpm}$ and a temperature of $180^{\circ} \mathrm{C}$. There is no evidence of degradation for BioPE, since there has been no continuous reduction in torque over time. The oil was more effective in reducing the torque after homogenizing the composites, as verified after $3 \mathrm{~min}$. 
The composites BioPE/WP and BioPE/WP/PE-g-MA presented in 10 min torques of approximately 2.5 N.m, indicating a $38.8 \%$ increase in torque, in comparison to BioPE. The addition of $30 \%$ wood powder hindered the melt flowing, since it acts as a filler and reduces molecular mobility, causing an increase in the viscosity of the composites, as also verified in the literature [37]. In this case, there is a higher energy consumption for processing the composites BioPE/WP and BioPE/WP/PE-g-MA, in relation to BioPE.

In the interval of 2 to 4 min there was a slight increase in the torque of the BioPE/WP/PE-g-MA composite compared to BioPE/WP, indicating a possible interaction between the compatibilizer PE-g-MA with the wood powder. It is believed that the maleic anhydride groups of PE-g-MA and the hydroxyl groups of wood powder have interacted [38], as shown in Figure 2. After 5.5 min the torque curves of the BioPE/WP and BioPE/WP/PE-g-MA composites are superimposed.

Despite containing 30\% wood powder, the BioPE/WP/oil composite showed a reduction in torque $(1.55$ N.m), compared to BioPE. The same trend of torque reduction occurred for the BioPE/WP/PE-g-MA/Oil (1.98 N.m) composite, compared to the BioPE/WP and BioPE/WP/PE-g-MA systems. Macaiba oil is acting as a plasticizer in composites, increasing molecular mobility, reducing viscosity and equilibrium torque (10 min). In this case, it is suggested macaíba oil is acting as a processing aid for composites, improving the melt flowing. In this way, macaíba oil is able to improve the flow properties and decrease the adherence of the melt with the machine components. Thus, energy consumption is saved and productivity can be increased.

The BioPE/WP/PE-g-MA/Oil composite showed a torque 27.7\% higher than the BioPE/WP/oil system, indicating that despite having the same proportion of wood powder (30\%), the plasticization mechanism was different. The different behavior of these composites is associated with the compatibilizer PE-g-MA, suggesting there was interaction between the functional groups maleic anhydride, the hydroxyls of wood powder and macaíba oil. As a consequence, there was a balance between the plasticizer effect and the restriction of filler mobility in the BioPE/WP/PE-g-MA/Oil composite, generating an intermediate torque curve between BioPE and the BioPE/WP and BioPE/WP/PE-g-MA systems. The literature $[40,41]$ reports that natural oils have technological potential to interact with wood powder, including to act as a compatibilizer.

\subsection{Scanning Electron Microscopy (SEM)}

Through scanning electron microscopy it was possible to evaluate the efficiency of the wood filler dispersion process in the BioPE matrix and the surface wetting capacity of the composites, as a way of evaluating the efficiency of the compatibilizing agent and the macaíba oil. Figure $3(a, b, c, d)$ illustrates the micrographs obtained by SEM from composites, with and without macaíba oil. In Figure 1 (a), the BioPE/WP composite showed a large amount of agglomerated wood fibers, indicating that there was poor dispersion during processing. In this case, due to the presence of agglomerates, a localized stress concentration can occur during the mechanical test, with the nucleation of cracks and generating a premature failure in the composite [42]. In addition, there is a weak adhesion between the wood fibers and BioPE. The poor adhesion occurs due to the high interfacial tension existing between the components, 
due to the hydrophilic nature of BioPE's wood and hydrophobic powder, which makes the interface with low resistance, corroborating the lower performance under the impact of this system [43].

In Figure 3 (b), it can be seen the BioPE/WP/oil composite did not present agglomerations, indicating that macaíba oil helped to disperse the wood fibers during processing. In addition, it presents well-adhered wood fiber in the BioPE matrix (see square) and, at the same time, poorly adhered particles (marked with a circle), with an interface without adhesion. However, clearly macaíba oil promoted a more stable morphology in the composite, improving the interfacial adhesion and the degree of dispersion of the fillers, confirming the better performance under the impact of the BioPE/WP/oil system, in relation to the BioPE/WP composite (Figure 4).

Figure 3 (c, d) shows that the addition of PE-g-MA and macaíba oil increased the interaction of the wood fiber and the BioPE matrix, improving the degree of interfacial adhesion. In this case, the applied stress is better distributed from BioPE to wood fiber, contributing to a higher performance under impact [44], as further on presented. At the same time, there is no evidence of delamination or agglomeration of fillers, suggesting that better distribution and dispersion occurred during processing. Apparently, the compatibilizer PE-g-MA favored higher efficiency of the level of wetting of the wood fiber by BioPE, suggesting interactions between the functional groups, as discussed in torque rheometry.

The composites BioPE/WP/PE-g-MA and BioPE/WP/PE-g-MA/oil presented strong interfaces, Figure 3 (c, d), reinforcing the idea that PE-g-MA acts as a proper compatibilizing agent in these systems. The interfacial adhesion between the fiber and the matrix is essential to obtain high mechanical properties in composites [45]. As the stress applied on the composite material is transferred from the matrix to the fibers through the interface, a good interfacial adhesion is necessary to optimize the mechanical properties [46].

\subsection{Impact Strength}

Figure 4 shows the impact strength of BioPE and composites with and without macaíba oil, respectively. BioPE presented the highest impact strength $(91.2 \mathrm{~J} / \mathrm{m})$, a typical ductile polymer value. The BioPE/WP composite reduced the impact strength by around $60 \%$, compared to neat BioPE. This occurred due to the addition of $30 \%$ wood powder (WP), since it is a stiff filler and, consequently, tended to weaken the ductile matrix [47]. The fillers act as stress concentrators, restricting the mobility of the matrix and reducing the plastic deformation [48]. The BioPE/WP/PE-g-MA composite increased the impact strength by $32.5 \%$, compared to BioPE/WP. The increase in impact strength is taken as an indication that the addition of PEg-MA promoted the interaction between the present phases, as seen in the torque rheometry and SEM. As a consequence, it strengthened the system interface, which is essential for the tension transfer between the phases $[49,50]$.

The BioPE/WP/oil composite showed a gain in impact strength of approximately $31 \%$ compared to the BioPE/WP, indicating macaíba oil increased flexibility, generating higher level of energy dissipation. Apparently, macaíba oil also minimizes the effect of the polaride difference between the hydrophobic 
matrix of BioPE and the wood powder with hydrophilic nature, improving the interaction at the interface, as verified in the SEM. In fact, the composites BioPE/WP/oil and BioPE/WP/PE-g-MA are resistant to impact within the experimental error range and, in this case, are comparable in this property. It is reasonable to suggest that macaíba oil is acting as a plasticizer, increasing the free volume and molecular mobility of the BioPE/WP/oil composite, contributing to increase the compatibility of impact properties.

The greatest impact strength was achieved with BioPE/WP/PE-g-MA/oil composite, with a value in the order of $56.8 \mathrm{~J} / \mathrm{m}$. The performance of this composite is the result of the combined behavior of the reinforcement element, compatibilizer and the macaíba oil. Figure 5 presents a schematic representation of the BioPE/WP/PE-g-MA/oil interaction. The compatibilizer PE-g-MA reacts with the hydroxyls of the wood powder and, at the same time, there is a physical entanglement with the BioPE polymer matrix chain. The macaíba oil has oleic acid in its constitution [51], which promotes interactions of hydrogen bonds with the hydroxyls present on the surface of the wood powder and plasticizes the composite, generating compatibility and increasing impact strength $[52,53]$.

The statistical evaluation was carried out to analyze the macaíba oil effect on impact strength. Therefore, similar composites were evaluated, that is, BioPE/WP; BioPE/WP/oil and BioPE/WP/PE-g-MA; BioPE/WP/PE-g-MA/oil. A significance level of $95 \%$ was adopted and the $t_{\text {table }}=2,446$. BioPE/WP and BioPE/WP/oil composites presented a $t_{\text {calculated }}=2.574$, indicating that macaíba oil provided significant increase in impact strength. On the other hand, the BioPE/WP/PE-g-MA and BioPE/WP/PE-g-MA/oil mixtures indicated a $t_{\text {calculated }}=2.132$ and, in this case, there is no significant difference in the impact strength of these composites $\left(t_{\text {calculated }}<t_{\text {table }}\right)$. Statistical results indicate that macaíba oil has the potential to make the BioPE/WP system compatible, generating a gain in impact strength. However, the BioPE/WP/PE-g-MA/oil hybrid composite, despite having a gain in impact strength with the addition of oil, was not as effective compared to the BioPE/WP/oil system. Such trend indicates that it is more feasible to use PE-g-MA or macaíba oil individually aiming at compatible BioPE/WP composite, in order to optimize the impact strength.

\subsection{Tensile Strength}

Figure 6 shows the results of the elastic modulus of BioPE and composites, with and without macaíba oil, respectively.

BioPE presented the lower elastic modulus with a value around $400 \mathrm{MPa}$, indicating that it is the most flexible material, as verified in the impact strength. The elastic modulus increased with the addition of $30 \%$ wood powder in the BioPE/WP composite, reaching a gain of $53 \%$, compared to neat BioPE. This increase is due to the fact that wood powder is more stiff than BioPE matrix and prevents its free mobility [54]. A more expressive increase in the elastic modulus was achieved for the BioPE/WP/PE-g-MA composite, with gains of $65.6 \%$ and $8.2 \%$, compared to BioPE and BioPE/WP, respectively. Thus, there is evidence that the compatibilizer PE-g-MA showed interfacial action, promoting a better adhesion between 
the BioPE matrix and the wood powder, contributing to increase the elastic modulus [55]. The higher performance in the stiffness of the BioPE/WP/PE-g-MA composite may be related to the greater wettability of BioPE with wood powder, as seen in the SEM (Figure 3c).

The composites BioPE/WP/oil and BioPE/WP/PE-g-MA/oil did not show significant differences between them, as they are within the margin of experimental error. In comparison to BioPE, the composites BioPE/WP/oil and BioPE/WP/PE-g-MA/oil increased $32.5 \%$ and 39\%, respectively. However, composites with macaíba oil became more flexible and reduced stiffness, compared to BioPE/WP and BioPE/WP/PEg-MA. This behavior can be explained by the plasticizing action of macaíba oil, which probably acts in the amorphous phase of BioPE, inserting itself between its macromolecules and favoring sliding and molecular mobility [56], as seen with the reduction of viscosity in torque rheometry. The BioPE/WP; BioPE/WP/oil composites and BioPE/WP/PE-g-MA; BioPE/WP/PE-g-MA/oil composites were evaluated by statistical test, with a $95 \%$ significance level and the $t_{\text {table }}=-2.446$. The BioPE/WP and BioPE/WP/oil composites presented a $t_{\text {calculated }}=-1.964$, while the BioPE/WP/PE-g-MA and BioPE/WP/PE-g-MA/oil systems indicated a value of $t_{\text {calculated }}=-2.183$. These results show that although macaíba oil reduced the elastic modulus, there was no drastic reduction in this property. In this case, even the macaíba oil increasing the flexibility of the composites kept the tensile elastic modulus high, even surpassing the neat BioPE.

The tensile strength results of BioPE and composites with and without macaíba oil are shown in Figure

The tensile strength of the BioPE/WP composite reduced approximately $10 \%$ compared to BioPE, indicating that the wood powder is acting as filler. At the same time, the BioPE/WP composite showed agglomerates of wood particles, as seen in Figure 3 (a), generating a concentration and intensification of the stress [57], contributing to the decrease in tensile strength. When the BioPE/WP composite was made compatible with PE-g-MA, the tensile strength reached the highest performance with $29.6 \mathrm{MPa}$, corresponding to gains of $39.6 \%$ and $54.9 \%$, compared to BioPE and the composite BioPE/WP. This behavior can be associated with good adhesion and homogeneous dispersion among the constituents of the composite, as verified in the SEM. The fracture surface morphology of the BioPE/WP/PE-g-MA composite showed a good wettability of the wood powder with the BioPE matrix, providing stress transfer from the matrix to the filler, resulting in an increase in tensile strength.

The BioPE/WP/oil composite showed a marked reduction in tensile strength, with decreases of $29.7 \%$ and $21.9 \%$, in relation to BioPE and the BioPE/WP composite, respectively. This behavior indicates that the macaíba oil plasticized, reducing the maximum resistance supported by the BioPE/WP/oil composite. The BioPE/WP/PE-g-MA/oil system did not significantly modify the tensile strength (22.6 MPa), only maintaining the value compared to BioPE. However, the BioPE/WP/PE-g-MA/oil composite showed a gain of $18.3 \%$, compared to BioPE/WP. Clearly, the addition of macaíba oil impaired the effect of wood powder reinforcement on the BioPE/WP/PE-g-MA composite, leading to a loss of mechanical strength due to the plasticizer effect. The statistical evaluation was carried out to analyze the effect of macaíba oil on the tensile strength, with a significance level of $95 \%$ and the $t_{\text {table }}=-2.446$. The comparative test was applied 
to similar composites, that is, BioPE/WP; BioPE/WP/oil and BioPE/WP/PE-g-MA; BioPE/WP/PE-g-MA/oil. The BioPE/WP and BioPE/WP/oil composites showed $t_{\text {calculated }}=-2.578$, while the BioPE/WP/PE-g-MA and BioPE/WP/PE-g-MA/oil systems indicated a value of $t_{\text {calculated }}=-2.613$. The tests indicated that $t_{\text {calculated }}<t_{\text {table }}$, therefore, there is a statistical difference in tensile strength. Such behavior suggests there was significant reduction in tensile strength, that is, macaíba oil contributed significantly to deteriorate this property, due to the plasticizer effect. As consequence, composites deformed at lower stresses.

\subsection{Flexural Modulus}

Figure 8 shows the results of flexural modulus of BioPE and composites, with and without macaíba oil, respectively. The BioPE/WP composite showed a flexural modulus value higher than the BioPE, with a gain of $89 \%$. A more expressive increase in the flexural modulus was verified with the BioPE/WP/PE-g-MA composite, reaching gains in the order of $140 \%$ and $26.9 \%$, in relation to BioPE and the BioPE/WP composite. The higher performance of the BioPE/WP/PE-g-MA system can be explained by the interactions triggered by PE-g-MA at the BioPE/wood powder interface, when hydroxyl groups $(\mathrm{OH})$ react with maleic anhydride (MA) providing greater anchoring to the composite $[58,59]$.

The addition of macaíba oil caused a significant decrease flexural modulus of the composites BioPE/WP/oil and BioPE/WP/PE-g-MA/oil, making them more flexible. The addition of macaíba oil to the composites, regardless of whether they are compatible or not, compromised the stiffness, corroborating the same trend of the elastic modulus. Such behavior is due to the diffusion of macaiba oil to the amorphous structure of BioPE, with a plasticizing effect and increasing molecular mobility [60]. The statistical test was performed to verify if there was significant reduction in the flexural modulus, with significance level of $95 \%$ and the $t_{\text {table }}=-2.446$. BioPE/WP and BioPE/WP/oil composites showed a $\mathrm{t}_{\text {calculated }}=-3.764$, while the BioPE/WP/PE-g-MA and BioPE/WP/PE-g-MA/oil systems indicated a value of $t_{\text {calculated }}=-4.183$. The statistical results demonstrated macaíba oil addition severely impairs the flexural modulus ( $\left.t_{\text {table }}>t_{\text {calculated }}\right)$. Therefore, if required rigid composite which will be submitted to flexural effort, macaíba oil should be avoided, as it impairs this property. The result is opposite to that presented by the elastic modulus, however it is important to mention that the mechanical effort is different for the two tensile tests.

\subsection{Shore D Hardness}

Figure 9 shows the results of Shore D hardness of BioPE and composites, with and without macaíba oil, respectively. It is observed that BioPE has the lowest Shore D hardness, due to its more flexible behavior, as seen in the impact strength and elastic modulus. The addition of $30 \%$ wood powder increased the Shore $D$ hardness of all composites, in relation to BioPE. The composites BioPE/WP and BioPE/WP/PE-gMA increased $10.7 \%$ and $11.2 \%$ when compared to BioPE. This is due the fillers are more stiff than the matrix, reducing mobility and increasing stiffness [61], as seen in the elastic modulus and flexural 
modulus. As a consequence, there is an increase in the penatration resistance, contributing to the increase in Shore D hardness of the composites.

The penatration resistance is a quick test to evaluate the influence of macaíba oil in the composites, as seen in Figure 9. The trend is the reduction in Shore D hardness of the composites, BioPE/WP and BioPE/WP/PE-g-MA, with the addition of macaíba oil, due to the increase in molecular spacing [62]. The composites BioPE/WP/oil and BioPE/WP/PE-g-MA/oil showed slight gains of $6 \%$ and $7.2 \%$, in relation to BioPE. These composites do not present significant differences between them, considering that they are within the margin of experimental error and, in this case, have penatration resistance comparable.

Shore $D$ hardness was assessed by the statistical test, with a $95 \%$ significance level and the $t_{\text {table }}=$ -2.446. Again, BioPE/WP; BioPE/WP/oil and BioPE/WP/PE-g-MA; BioPE/WP/PE-g-MA/oil composites were evaluated in order to analyze the effect of macaíba oil. The tests indicated a $t_{\text {calculated }}=-1.841$ for the BioPE/WP and BioPE/WP/oil composites, while the BioPE/WP/PE-g-MA and BioPE/ WP/PE-g-MA/oil systems presented $t_{\text {calculated }}=-1.893$. The results show that there is no significant difference in Shore $D$ hardness between similar composites ( $\left.t_{\text {calculated }}>t_{\text {table }}\right)$, that is, the addition of macaíba oil did not severely impact this property.

Heat Deflection Temperature (HDT)

Heat deflection temperature (HDT) is an extremely important property in the area of polymers, since it indicates the dimensional stability of the materials, at high temperatures $[63,64]$. Figure 10 shows the results of the heat deflection temperature of BioPE and composites, with and without macaíba oil, respectively. It is observed that the HDT value for BioPE was $70.3^{\circ} \mathrm{C}$, value close of the literature [65].

The heat deflection temperature is strongly influenced by the stiffness of the system, with a tendency to increase the deflection temperature, with the addition of the elastic modulus [66]. The composites BioPE/WP and BioPE/WP/PE-g-MA showed very significant increases in HDT, with gains of $44.1 \%$ and $48.1 \%$, compared to BioPE. These results indicate that the addition of $30 \%$ wood powder in BioPE improved the thermomechanical resistance, impacting on a greater structural stability at higher temperatures. In comparative terms, the heat deflection temperature of the composites BioPE/WP and BioPE/WP/PE-g-MA was, on average, $34^{\circ} \mathrm{C}$ higher than that of BioPE, suggesting that the incorporation of a stiff filler contributed to the corresponding increase this property, corroborating the results of elastic modulus and flexural modulus. Apparently, the influence of the compatibilizer PE-g-MA was not significant in this HDT property, since the composites BioPE/WP and BioPE/WP/PE-g-MA are within the experimental error margin.

The composites BioPE/WP and BioPE/WP/PE-g-MA additivated with macaíba oil showed gains of $26.3 \%$ and $30.3 \%$, in relation to BioPE. However, the performance of these composites with macaíba oil decreased when compared to similar BioPE/WP and BioPE/WP/PE-g-MA without oil, indicating that the plasticizer effect impairs this property, due to reduced stiffness, as verified in the tensile and flexion tests. 
The statistical test with a $95 \%$ significance level and the $t_{\text {table }}=-3.182$ was applied to analyze the impact of macaíba oil. BioPE/WP and BioPE/WP/oil composites showed a $t_{\text {calculated }}=-2.324$, while the BioPE/WP/PE-g-MA and BioPE/WP/PE-g-MA/oil composites indicated a $t_{\text {calculated }}=-2.187$. As $t_{\text {calculated }}>$ $t_{\text {table }}$ there was no significant reduction in heat deflection temperature (HDT), with the addition of macaíba oil. The results indicate that although macaíba oil reduces the HDT of the composites, there was no severe loss in this property, contributing to keep good thermomechanical stability.

The increase in thermomechanical resistance caused by the presence of $30 \%$ wood powder provides an important technological contribution to the BioPE/wood powder composites, since it significantly increased HDT. Although macaíba oil reduced the HDT value, its presence still keeps high HDT and, at the same time, improves processability, as seen in torque rheometry.

\subsection{Differential Scanning Calorimetry (DSC)}

The melting, crystallization parameters and the degree of crystallinity of BioPE and composites are summarized in Table 4. The DSC scans obtained during the second heating cycle can be seen in Figure $11(a, b)$.

Table 4. Melting and crystallization parameters of BioPE and composites.

\begin{tabular}{|llllll|}
\hline Samples & $\mathbf{T c}\left({ }^{\circ} \mathrm{C}\right)$ & $\Delta \mathrm{Hc}(\mathrm{J} / \mathrm{g})$ & $\operatorname{Tm}\left({ }^{\circ} \mathrm{C}\right)$ & $\Delta \mathrm{Hm}(\mathrm{J} / \mathrm{g})$ & $\mathrm{Xc}(\%)$ \\
\hline BioPE & 115.6 & 187.3 & 133.9 & 176.6 & 60.2 \\
\hline BioPE/WP & 119.1 & 126.0 & 132.8 & 115.2 & 56.2 \\
\hline BioPE/WP/Oil & 118.3 & 94.7 & 131.6 & 99.1 & 48.3 \\
\hline BioPE/WP/PE-g-MA & 117.9 & 117.0 & 132.8 & 107.7 & 61.2 \\
\hline BioPE/WP/Pe-g-MA/Oil & 118.4 & 109.8 & 131.0 & 104.4 & 59.4 \\
\hline
\end{tabular}

${ }^{*} \mathrm{~T}_{\mathrm{m}}=$ Melting peak temperature; $\mathrm{T}_{\mathrm{c}}=$ Crystallization peak temperature; $\Delta \mathrm{H}_{\mathrm{c}}=$ Crystallization enthalpy; $\Delta \mathrm{H}_{\mathrm{f}}=$ Melting enthalpy; $\mathrm{X}_{\mathrm{c}}=$ Degree of crystallinity, $\mathrm{X}_{\mathrm{c}}=\Delta \mathrm{H}_{\mathrm{f}} / \mathrm{w}^{\star} \Delta \mathrm{H}_{0}$, where: $\mathrm{w}=$ mass fraction of BioPE; $\Delta \mathrm{H}_{0}=$ Melting enthalpy BioPE at $100 \%$ of crystallinity, $293 \mathrm{~J} / \mathrm{g}[21]$.

In Table 4, it is possible to see a single melting peak around $133.9^{\circ} \mathrm{C}$, commonly found in a polymeric polyethylene matrix [67]. The melting temperature $(\mathrm{Tm})$ of the composites did not change significantly in relation to BioPE, only subtle changes. Composites additivated with macaíba oil, although not a significant variation, tended to have the lowest $\mathrm{Tm}$. As the reduction in the melting temperature is often associated with the degree of crystals perfection [68], possibly macaíba oil may have helped to diffuse small particles of wood powder to the amorphous region of BioPE, reducing its degree of crystals perfection. There is a marked reduction in the melting enthalpy $(\Delta \mathrm{Hf})$ of the composites compared to BioPE, due to the high content of wood powder $(30 \%)$ and the reduction of the BioPE content in the 
formulation. When the composites BioPE/WP and BioPE/WP/PE-g-MA are additivated with macaíba oil, there is a more evident reduction in the melting enthalpy, suggesting that the presence of macaíba oil reduces the energy consumption to melt the crystals, corroborating with torque rheometry.

The crystallization temperature (Tc) of the composites increased in relation to neat BioPE, indicating that the wood powder accelerates the crystallization process. From a practical point of view, injection molded composites can be removed hotter from the molds, as they solidify at higher temperatures. The enthalpy of crystallization of composites requires less energy to promote crystallization, compared to BioPE. The composites BioPE/WP and BioPE/WP/PE-g-MA with macaíba oil show the lowest enthalpy of crystallization, suggesting that the oil contributed to the structural organization during cooling.

Biopolyethylene showed a degree of crystallinity in the order of $60.2 \%$, a value close to reported in literature [69]. The BioPE/WP composite showed $56.2 \%$ crystallinity, a reduction compared to BioPE, due to poor wettability and the low interfacial interaction between BioPE and wood powder, as seen in the SEM (Figure 3a). When the BioPE/WP composite contains macaiba oil, a significant reduction occurred in the degree of crystallinity, with a value around $48.3 \%$. As macaíba oil is acting as a plasticizer in the BioPE/WP composite, increasing molecular mobility, the degree of crystallinity would have increased or at least maintained the crystallinity of the BioPE/WP composite without oil. Apparently, the addition of macaíba oil directly to the BioPE/WP system hindered the formation of crystals, reinforcing the hypothesis that the oil helped diffuse small particles of wood powder into the amorphous chains of BioPE, creating difficulties for molecular packaging and reducing crystallinity [70].

The composites BioPE/WP/PE-g-MA and BioPE/WP/PE-g-MA/oil showed a degree of crystallinity similar to neat BioPE, indicating that PE-g-MA acts in order to improve the structural organization, increasing the degree of crystallinity. This finding is related to a better dispersion of wood powder in BioPE matrix, as well as a greater wettability between the phases, as verified in the SEM.

\subsection{Thermogravimetry (TG)}

Figure 12 illustrates the TG's curves of BioPE and composites, with and without macaíba oil, respectively. It is observed that BioPE presented only one stage of decomposition at temperatures above $400^{\circ} \mathrm{C}$, which guarantees good thermal stability for the process conditions used. A reduction in thermal stability is seen for all composites, compared to BioPE, due to the presence of wood powder [71]. The composites presented three evident decomposition steps, the first in the range of room temperature up to $100^{\circ} \mathrm{C}$, attributed to the loss of water by desorption, considered a thermal event of physical origin, as there is no loss of mass of the material [72]. The second loss after $250^{\circ} \mathrm{C}$ is attributed to the decomposition of wood powder components, which are cellulose, hemicelluloses and lignin, as well as macaiba oil [73]. The third mass loss event is attributed to the decomposition of the BioPE chain and remaining lignin.

In order to evaluate the relative thermal stability of the composites, the temperatures for $10 \%$ and $50 \%$ of mass loss $\left(T_{0.1}\right.$ and $\left.T_{0.5}\right)$ were calculated and are shown in Table 5. BioPE is the most thermally stable material, as verified with $T_{0.1}$ and $T_{0.5}$, i.e., there is a loss of mass at higher temperatures. The BioPE/WP 
composite showed the lowest thermal stability at $10 \%$ of mass loss, since it started to decompose at a lower temperature, around $312^{\circ} \mathrm{C}$. This behavior is related to the weak interactions between BioPE and wood powder, as seen in the mechanical results presented previously, as well as in the morphological analysis (Figure 3a). The addition of the BioPE/WP composite with macaíba oil moved the weight loss $\left(T_{0.1}\right)$ to a higher temperature, around $325^{\circ} \mathrm{C}$. The use of macaíba oil clearly improved the interfacial adhesion between BioPE and wood powder (Figure 3b), generating an increase in the thermal stability of the BioPE/WP/oil composite. The literature [74] has shown that the use of natural oil in composites can improve thermal stability, with an effect similar to a compatibilizing agent.

The composites BioPE/WP/PE-g-MA and BioPE/WP/PE-g-MA/oil showed a higher stability temperature for the loss of mass in $\mathrm{T}_{0.1}$, which is an indication of interaction between the components of the mixture, as seen in torque rheometry and SEM. As a consequence, from the greater synergism there was a stabilizing effect. The literature [75] indicates that the improvement in thermal properties reflects the stabilization of morphology, in which the components present interfacial interactions, with better compatibility. The $50 \%$ mass loss temperature practically does not change between composites, only similar losses.

Table 5. Thermal stability of neat BioPE and composites, with and without macaíba oil.

\begin{tabular}{|llll|}
\hline Samples & $\mathrm{T}_{0.1}\left({ }^{\circ} \mathrm{C}\right)$ & $\mathrm{T}_{0.5}\left({ }^{\circ} \mathrm{C}\right)$ & Residue at $520^{\circ} \mathrm{C}(\%)$ \\
\hline BioPE & 433.8 & 467.2 & 0.0 \\
\hline BioPE/WP & 312.9 & 461.5 & 1.1 \\
\hline BioPE/WP/Oil & 324.9 & 458.1 & 1.4 \\
\hline BioPE/WP/PE-g-MA & 341.0 & 461.3 & 2.9 \\
\hline BioPE/WP/PE-g-MA/Oil & 333.4 & 468.9 & 3.2 \\
\hline
\end{tabular}

In Table 5, the composites at $510^{\circ} \mathrm{C}$ showed residual carbonaceous material, resulting from decarboxylation, decomposition and depolymerization of cellulose and hemicellulose fragments, as reported in literature $[76,77]$.

\subsection{Water Absorption}

The degree of water absorption is an important characteristic to be evaluated in composites with natural fibers, as it assesses the potential of these materials for use in certain applications, such as in external applications in which there is contact with moisture [78]. Figure 13 shows the water absorption curve for BioPE and composites, with and without macaíba oil, respectively.

BioPE practically did not absorb water during $1728 \mathrm{~h}$, suggesting a stability against humidity, due to the hydrophobic character of this polymer. The composites showed a fast water absorption in the first 200 hours, due to wood powder. Natural fibers have a hydrophilic behavior, due to the presence of hydroxyl 
groups in their structure, thus absorbing water [79]. Over time, the curve changes its slope smoothly until it reaches a linear level, which represents the level of moisture saturation.

The macaíba oil and the compatibilizer, impact on the water absorption kinetics, as shown in Figure 13. The BioPE/WP composite showed the highest level of water absorption in $1728 \mathrm{~h}$, due to the ease of diffusion of water molecules among micro-voids polymer chains, as well as defects resulting from the low adhesion between BioPE and wood powder, as seen in the SEM. When the BioPE/WP composite was additivated with macaíba oil, a reduction in water absorption is verified. This finding indicates that macaíba oil acts as a barrier effect, reducing the diffusion of water into the composite.

The composites BioPE/WP/PE-g-MA and BioPE/WP/PE-g-MA/oil significantly reduced water absorption in $1728 \mathrm{~h}$, compared to the BioPE/WP and BioPE/WP/oil systems. This finding indicates that there was an increase in the interaction between the components of the composites, reinforcing the reactions proposed in Figures 2 and 5 . The literature $[80,81]$ attributed the reduction in water absorption to the reaction of the hydrophilic groups $-\mathrm{OH}$ present in the fibers with the groups anhydrides present in the compatibilizer. As a consequence, there is a decrease in the availability of hydrophilic sites in wood powder, impacting on the reduction of water absorption.

\section{Conclusions}

The impact of macaíba oil on bio-polyethylene/wood powder composites compatibilized with PE-g-MA was investigated. The addition of macaíba oil improved the processability of the composites, with a plasticizer effect. However, the presence of macaíba oil tended to reduce the elastic modulus, Shore $D$ hardness and heat deflection temperature, in comparison to composites without macaíba oil. In contrast, the use of macaíba oil improved the interfacial adhesion between BioPE and wood powder, generating gains in impact strength and reduction in water absorption. This last result is important, since the decrease in water absorption can increase dimensional stability. When the composite formulation is BioPE/wood powder/PE-g-MA/macaíba oil, good results are achieved, generating a synergism of properties and processing. The results indicate a good perspective of application of these composites, with a reduced price due to the possibility of reusing up to $30 \%$ of a material that would be discarded. In addition, the harmful effect of this residue on the environment can be minimized and added value to a rejected material.

\section{Declarations}

\section{Acknowledgments}

The authors thank UFCG for the infrastructure of the laboratories, National Council for Scientific and Technological Development - CNPq, Coordination for the Improvement of Higher Education Personnel (CAPES) for financial support and Addivant for the donation of the compatibilizer (PE-g-MA). 


\section{References}

[1] Luna, C. B. B.; Siqueira, D. D.; Ferreira, E. S. B.; Silva, W. A.; Nogueira, J. A. S.; Araújo, E. M. From disposal to technological potential: reuse of polypropylene waste from industrial containers as a polystyrene impact modifier. Sustainability 2020, 12(13), 5272-5291.

[2] Marinho, V. A. D.; Almeida, T. G.; Carvalho, L. H.; Canedo, E. L. Aditivação e biodegradação de compósitos PHB/babaçu. Revista Eletrônica de Materiais e Processos 2018, 13(1), 37-41.

[3] Ramos, R. R. F.; Siqueira, D. D.; Wellen, R. M. R.; Leite, I. L.; Glenn, G. M.; Medeiros, E. S. Development of green composites based on polypropylene and corncob agricultural residue. Journal of Polymers and the Environment 2019, 27(5), 1677-1685.

[4] Oliveira, T. A.; Barbosa, R.; Mesquita, A. B. S.; Ferreira, J. H. L.; Carvalho, L. H.; Alves, T. S. Fungal degradation of reprocessed PP/PBAT/thermoplastic starch blends. Journal of Materials Research and Technology 2020, 9(2), 2338-2349.

[5] Siqueira, D. D.; Luna, C. B. B.; Araújo, E. M.; Ferreira, E. S. B.; Wellen, R. M. R. Biocomposites based on PCL and macaiba fiber. Detailed characterization of main properties. Materials Research Express 2019, 6(9), 095335.

[6] Wearn, Y. N.; Montagna, L. S.; Passador, F. R. Coconut fiber/LDPE composites: effect of surface treatment of coconut fibers to produced green composites. Matéria (Rio J.) 2020, 25(1), e-12548.

[7] Oliveira, T. A.; Mota, I. O.; Mousinho, F. E. P.; Barbosa, R.; Carvalho, L. H.; Alves, T. S. Biodegradation of mulch films from poly(butylene adipate co-terephthalate), carnauba wax, and sugarcane residue. Journal os Applied Polymer Science 2019, 136(47), 48240.

[8] Luna, C. B. B.; Siqueira, D. D.; Ferreira, E. S. B.; Araújo, E. M.; Wellen, R. M. R. Reactive compatilization of PCL/WP upon addition of PCL-MA. Smart option for recycling industry. Materials Research Express 2019, 6(12), 125317.

[9] Filho, P. A. F.; Oliveira, T. P.; Caetano, M. R. S.; Araújo, I. M. S.; Figueiredo, F. C.; Júnior, J. R. S. Enhancement of the photodegradative potential of polymer composites containing babassu fiber. Materials Research 2020, 23(2), e20190438.

[10] Lotfi, A.; Li, H.; Dao, D. V.; Prusty, G. Natural fiber-reinforced composites: A review on material, manufacturing, and machinability. Journal of Thermoplastic Composite Materials. Epub ahead of print 28 April 2019. DOI: 10.1177/0892705719844546.

[11] Mei, L. H.; Oliveira, N. Caracterização de um compósito polimérico biodegradável utilizando Poli ( $\varepsilon$ caprolactona) e borra de café. Polímeros 2017, 27(1), 99-109. 
[12] Ferreira, E. S. B.; Luna, C. B. B.; Araújo, E. M.; Siqueira, D. D.; Wellen, R. M. R. Polypropylene/wood powder composites: Evaluation of PP viscosity in thermal, mechanical, thermomechanical, and morphological characters. Journal of Thermoplastic Composite Materials. Epub ahead of print 09 October 2019. DOI: 10.1177/0892705719880958.

[13] Siqueira, D. D.; Luna, C. B. B.; Ferreira, E. S. B.; Araújo, E. M.; Wellen, R. M. R. Tailored PCL/Macaíba fiber to reach sustainable biocomposites. Journal of Materials Research and Technology 2020, 9(5), 9691-9708.

[14] Li, M.; Pu, Y.; Thomas, V. M.; Yoo, C. G.; Ozcan, S.; Deng, Y.; Nelson, K.; Ragauskas, A. J. Recent advancements of plant-based natural fiber-reinforced composites and their applications. Composites Part B: Engineering 2020, Volume 200(11), 1-20.

[15] Mertens, O.; Krause, K. C.; Weber, M.; Krause, A. Performance of thermomechanical wood fibers in polypropylene composites. Wood Material Science \& Engineering 2020, 15(2), 114-122.

[16] Bezerra, E. B.; França, D. C.; Morais, D. D. S.; Siqueira, D. D.; Araújo, E. M.; Wellen, R. M. R. Toughening of bio-PE upon addition of PCL and PEgAA. REM - International Engineering Journal 2019, 72(3), $469-478$.

[17] Tarrés, Q.; Ardanuy, M. Evolution of interfacial shear strength and mean intrinsic single strength in biobased composites from bio-polyethylene and thermo-mechanical pulp-corn stover fibers. Polymers $2020,12(6), 1-16$.

[18] Ehman, N. V.; Nagy, D. I.; Felissia, F. E.; Vallejos, M. E.; Quispe, I.; Area, M. C.; Carrasco, G. C. Biocomposites of bio-polyethylene reinforced with a hydrothermal-alkaline sugarcane bagasse pulp and coupled with a bio-based compatibilizer. Molecules 2020, 25(9), 1.16.

[19] Hossain, M. S.; Razzak, M.; Uddin, M. B.; Chowdhury, A. M. S.; Khan, R. A. Physico-mechanical properties of jute fiber-reinforced LDPE-based composite: effect of disaccharide (sucrose) and gamma radiation. Radiation Effects and Defects in Solids 2020, 175(5), 516-528.

[20] Velis, H. H.; Golzar, M.; Yousefzade, O. Composites based on HDPE, jute fiber, wood, and thermoplastic starch in tubular pultrusion die: The correlation between mechanical performance and microstructure. Advanves in Polymer Technology 2018, 37(8), 3483-3491.

[21] Morais, J. A.; Gadioli, R.; Paoli, M. A. Curaua fiber reinforced high-density polyethylene composites: effect of impact modifier and fiber loading. Polímeros 2016, 26(2), 115-122.

[22] Castro, B. D.; Faria, P. E.; Vieira, L. M. G.; Rubio, C. V. C.; Maziero, R.; Rodrigues, P. C. M.; Rubio, J. C. C. Recycled green PE composites reinforced with woven and randomly arranged sisal fibres processed by hot compression moulding. Acta Technologica Agriculturae 2020, 23(2), 81-86.

[23] Seifu, B.; Singh, B.; Gutu, J. M.; Legesse, D. Mechanical behaviours of hybrid ensete/sisal fiber, reinforced polyethylene composite materials for injection moulding. SN Applied Sciences 2020, 2(4), 1-25. 
[24] Bazan, P.; Nosal, P.; Kozub, B.; Kuciel, S. Biobased polyethylene hybrid composites with natural fiber: mechanical, thermal properties, and micromechanics. Materials 2020, 13(13), 1-13.

[25] Amoako, G.; Amoah, P. M.; Sam, F.; Sackey, S. S. Some mechanical properties of coconut fiber reinforced polyethylene composite to control environmental waste in Ghana. Energy and Environment Research 2018, 8(1), 1-9.

[26] Duarte, I. D. Rheological behavior of hybrid composites made of polyethylene/cotton fiber/montmothilonite clay. Graduation Conclusion Thesis, Federal University of Rio Grande do Norte, Natal-Brazil, 2019.

[27] Bosenbecker, M. W.; Cholant, G. M.; Silva, G. E. H.; Paniz, O. G.; Carreño, N. L. V.; Marini, J.; Oliveira, A. D. Mechanical characterization of HDPE reinforced with cellulose from rice husk biomass. Polímeros 2019, 29(4), e2019058.

[28] Gulitah, V.; Liew, K. C. Morpho-mechanical properties of wood fiber plastic composite (WFPC) based on three different recycled plastic codes. International Journal of Biobased Plastics 2019, 1(1), 22-30.

[29] Murayama, K.; Ueno, T.; Kobori, H.; Kojima, Y.; Suzuki, S.; Aoki, K.; Ito, H.; Ogoe, S.; Okamoto, M. Mechanical properties of wood/plastic composites formed using wood flour produced by wet ball-milling under various milling times and drying methods. Journal of Wood Science 2019, 65(5), 1-10.

[30] Castro, D. O.; Passador, F.; Filho, A. R.; Frollini, E. Use of castor and canola oils in "biopolyethylene" curauá fiber composites. Composites Part A: Applied Science and Manufacturing 2017, 95(4), 22-30.

[31] Koohestani, B.; Darban, A. K.; Mokhtari, P.; Yilmaz, E.; Darezereski, E. Comparison of different natural fiber treatments: a literature review. International Journal of Environmental Science and Technology 2019, 16(7), 629-642.

[32] Kumar, S. S.; Anbumalar, V. Selection and Evaluation of Natural Fibers - A Literature Review. IJISET International Journal of Innovative Science, Engineering \& Technology 2015, 2(11), 929-939.

[33] Poleto, M. Effect of styrene maleic anhydride on physical and mechanical properties of recycled polystyrene wood flour composites. Maderas. Ciencia y tecnología 2016, 18(4), 533-542.

[34] Poleto, M. Mechanical, dynamic mechanical and morphological properties of composites based on recycled polystyrene filled with wood flour wastes. Maderas. Ciencia y tecnología 2017, 19(4), 433-442.

[35] Amaral, F. P.; Broetto, F.; Batistella, C. B.; Jorge, S. M. A. Extração e caracterização qualitativa do óleo da polpa e amendoas de frutos de macaúba coletada na região de Botucatu - SP. Revista Energia na Agricultura 2011, 26(1), 12-20.

[36] Feng, C.; Li, Z.; Wang, Z.; Wang, B.; Wang, Z. Optimizing torque rheometry parameters for assessing the rheological characteristics and extrusion processability of wood plastic composites. Journal of 
Thermoplastic Composite Materials 2019, 32(1), 123-140.

[37] Ogah, A. O.; Afiukwa, J. N.; Nduji, A. A. Characterization and comparison of rheological properties of agro fiber filled high-density polyethylene bio-composites. Open Journal of Polymer Chemistry 2014, 4(1), 12-19.

[38] Ferreira, E. S. B.; Luna, C. B. B.; Araújo, E. M.; Siqueira, D. D.; Wellen, R. M. R. Polypropylene/wood powder/ethylene propylene diene monomer rubber-maleic anhydride composites: Effect of PP melt flow index on the thermal, mechanical, thermomechanical, water absorption, and morphological parameters. Polymer Composites. Epub ahead of print 06 October 2020. DOI: 10.1002/pc.25841.

[39] Baptista, C. A.; Canevarolo, S. V. Grafting polypropylene over hollow glass microspheres by reactive extrusion. Polímeros 2019, 29(3), e2019037.

[40] Poletto, M. Maleated soybean oil as coupling agent in recycled polypropylene/wood flour composites: Mechanical, thermal, and morphological properties. Journal of Thermoplastic Composite Materials 2019, 32(8), 1056-1067.

[41] Poletto, M. Natural oils as coupling agents in recycled polypropylene wood flour composites: Mechanical, thermal and morphological properties. Journal of Thermoplastic Composite Materials 2020, 28(7), 443-450.

[42] França, D. C.; Almeida, T. G.; Abels, G.; Canedo, E. L.; Carvalho, L. H.; Wellen, R. M. R.; Haag, K.; Koschek, K. Tailoring PBAT/PLA/Babassu films for suitability of agriculture mulch application. Journal of Natural Fibers 2019, 16(7), 933-943.

[43] Seixas, J. N.; Granada, J. E.; Melo, C. C. N.; Silva, G. E. H.; Passador, F. R.; Cholant, G. M.; Oliveira, A. D.; Beatrice, C. A. G.; Gonçalves, M. R. F.; Carreno, N. N. L. V. Compósitos de polipropileno reforçados com fibras naturais do talo da banana em diferentes granulometrias. Revista Brasileira de Engenharia e Sustentabilidade 2018, 5(1), 32-37.

[44] Jiang, X.; Wang, J.; Wu, G.; Peng, X.; Ma, X. Significant reinforcement of polypropylene/wood flour composites by high extent of interfacial interaction. Journal of Thermoplastic Composite Materials 2019, 32(5), 577-592.

[45] Guo, C.; Li, L.; Li, H. Evaluation of interfacial compatibility in wood flour/polypropylene composites by grafting isocyanate silane coupling agent on polypropylene. Journal of Adhesion Science and Technology 2019, 33(5), 468-478.

[46] Guo, C.; Li, L.; Li, H. Evaluation of interfacial compatibility in wood flour/polypropylene composites by grafting isocyanate silane coupling agent on polypropylene. Journal Journal of Adhesion Science and Technology 2019, 33(5), 468-478. 
[47] Hao, X.; Yi, X.; Sun, L.; Tu, D.; Wang, Q.; Ou, R. Mechanical properties, creep resistance, and dimensional stability of core/shell structured wood flour/polyethylene composites with highly filled core layer. Construction and Building Materials 2019, 226(11), 879-887.

[48] Lin, H.; Li, R.; Li, D.; Huang, Z.; Pang, J.; X.; Liu, W.; Yang, W. Hydrophobic wood flour derived from a novel $\mathrm{p}-\mathrm{TsOH}$ treatment for improving interfacial compatibility of wood/HDPE composites. Cellulose 2020, 27(2), 4053-4065.

[49] Anbupalani, M.; Venkatachalam, C. D.; Rathanasamy, R. Influence of coupling agent on altering the reinforcing efficiency of natural fibre-incorporated polymers - A review. Journal of Reinforced Plastics and Composites 2020, 39(13-14), 520-544.

[50] Latif, R.; Wakeel, S.; Khan, N. Z.; Siddiquee, A. N.; Verma, S. L.; Khan, Z. A. Surface treatments of plant fibers and their effects on mechanical properties of fiber-reinforced composites: A review. Journal of Reinforced Plastics and Composites 2019, 38(1), 15-30.

[51] Venancio, M. M. H.; Mazzafera, P.; Carvalho, C. L.; Silveira, L. H.; Filho, J. A. A.; Bazzo, B. R.; Colombo, C. A. Teor de óleo e perfil de ácidos graxos durante o desenvolvimento de frutos de macaúba. $6^{\circ}$ Congresso da Rede Brasileira de Tecnologia de Biodiesel, Rio Grande do Norte, Natal, p. 333-334, 2016.

[52] Poletto, M. Compósitos termoplásticos com madeira - uma breve revisão. Revista Interdisciplinar da Ciência Aplicada 2017, 2(4), 42-48.

[53] Hejna, A.; Romatowska, M. P.; Kosmela, P.; Zedler, L.; Korol, J.; Formela, K. Recent advances in compatibilization strategies of wood-polymer composites by isocyanates. Wood Science and Technology 2020, 54(7), 1091-1119.

[54] Ali, J. B.; Danladi, A.; Bukhari, M. M.; Mamza, P.; Zurina, M. Effects of Org-MMT on mechanical and morphological properties of HDPE/ HD-g-MAH /maize-cobs nanocomposites. SLU Journal of Science and Technology 2020, 1(1), 24-32.

[55] Migneault, S.; Kounaa, A.; Perré, P.; Rieldl, B. Effects of wood fiber surface chemistry on strength of wood-plastic composites. Applied Surface Science 2015, 343(7),11-18.

[56] Han, Y.; Shi, J.; Mao, L.; Wang, Z.; Zhang, L. Improvement of compatibility and mechanical performances of PLA/PBAT composites with epoxidized soybean oil as compatibilizer. Industrial \& Engineering Chemistry Research 2020, 59(50), 21779-21790.

[57] Zhang, Q.; Lu, W.; Zhou, L.; Zhang, D.; Cai, H.; Lin, X. Tensile and flammability characterizations of corn straw slagging/high-density polyethylene composites. Journal of Thermoplastic Composite Materials. Epub ahead of print 08 April 2019. DOI: 10.1177/0892705719830459.

[58] Todkar, S. S.; Patil, S. A. Review on mechanical properties evaluation of pineapple leaf fibre (PALF) reinforced polymer composites. Composites Part B: Engineering 2019, 174(10), 1-16. 
[59] Pickering, K. L.; Efendy, M. G. A.; Le, T. M. A review of recent developments in natural fibre composites and their mechanical performance. Composites Part A Applied Science and Manufacturing 2016, 83(4), 98-112.

[60] Wu, H.; Xu, D.; Zhou, Y.; Gao, C.; Guo, J.; He, W.; Qin, S. Tung oil anhydride modified hemp fiber/polypropylene composites: the improved toughness, thermal stability and rheological property. Fibers and Polymers 2020, 21(10), 2084-2091.

[61] Poletto, M. Polypropylene-based wood-plastic composites: Effect of using a coupling agent derived from a renewable resource. Maderas. Ciencia y tecnología 2017, 19(3), 265-272.

[62] Sommer, W. Plasticizer. In: Gachter, R \& Muller, H. Plastics Additives Handbook. $2^{\circ}$ edition, Hanser, Munich, 1985.

[63] Luna, C. B. B.; Silva, D. F.; Araújo, E. M.; Mélo, T. J. A.; Oliveira, A. D. Efeito dos agentes de compatibilização SBS e SEBS-MA no desempenho de misturas de poliestireno/resíduo de borracha de SBR. Matéria (Rio J.) 2016, 21(3), 632-646.

[64] Rusayyis, M. A. B.; Schiraldi, D. A.; Maia, J. Property/morphology relationships in SEBScompatibilized HDPE/poly(phenylene ether) blends. Macromolecules 2018, 51(16), 6513-6523.

[65] Bezerra, E. B.; França, D. C.; Morais, D. D. S.; Silva, I. D. S.; Siqueira, D. D.; Araújo, E. M.; Wellen, R. M. R. Compatibility and characterization of Bio-PE/PCL blends. Polímeros 2019, 29(2), e2019022.

[66] Luna, C. B. B.; Siqueira, D. D.; Araújo, E. M.; Wellen, R. M. R. Tailoring PS/PPrecycled blends compatibilized with SEBS. Evaluation of rheological, mechanical, thermomechanical and morphological characters. Materials Research Express 2019, 6(7), 075316.

[67] Firmino, H. C. T.; Chagas, T. F.; Melo, P. M. A.; Silva, L. B. Caracterização de compósitos particulados de polietileno de alta densidade/pó de concha de molusco. Matéria (Rio J.) 2017, 22(4), 1-12.

[68] Wolak, J. E.; White, J. L. Factors that allow polyolefins to form miscible blends: polyisobutylene and head-to-head polypropylene. Macromolecules 2005, 38, 10466-10471.

[69] Bosenbecker, M. W.; Croche, S.; Cholant, G.; Rosa, P.; Passador, F.; Marini, J.; Oliveira, A. Propriedades térmicas de compósitos de polietileno de alta densidade reforçados com celulose. Revista Brasileira de Engenharia e Sustentabilidade 2018, 5(1), 7-12.

[70] Machado, M. L. C.; Pereira, N. C.; Miranda, L. F.; Terence, M. C.; Pradella, J. G. C. Estudo das propriedades mecânicas e térmicas do polímero poli-3-hidroxibutirato (PHB) e de compósitos PHB/Pó de madeira. Polímeros: Ciência e Tecnologia 2010, 20(1), 65-71.

[71] Kaymakci, A.; Gulec, T.; Hosseinihashemi, S. K.; Ayrilmis, N. Physical, mechanical and thermal properties of wood/zeolite/plastic hybrid composites. Maderas. Ciencia y tecnología 2017, 19(3), 339- 
[72] Garcia, D. P.; Caraschi, J. C.; Ventorim, G. Decomposição térmica de pellets de madeira por TGA. HOLOS 2016, 32(1), 327-339.

[73] Poletto, M. Effect of extractive content on the thermal stability of two wood species from Brazil. Maderas. Ciencia y tecnología 2016, 18(3), 435-442.

[74] Poletto, M.; Zattera, A. J.; Santana, R. M. C. Effect of natural oils on the thermal stability and degradation kinetics of recycled polypropylene wood flour composites. Polymer Composites 2014, 35(10), 1935-1942.

[75] Poletto, M. Natural oils as coupling agents in recycled polypropylene wood flour composites: Mechanical, thermal and morphological properties. Polymers and Polymer Composites 2020, 28(7), 443450.

[76] Vijay, R.; Singaravelu, D. L.; Vinod, A.; Sanjay, M. R.; Siengchin, S. Characterization of alkali-treated and untreated natural fibers from the stem of parthenium hysterophorus. Journal of Natural Fibers. Epub ahead of print 09 May 2019. DOI: 10.1080/15440478.2019.1612308.

[77] Vijay, R.; Singaravelu, D. L.; Vinod. A.; Sanjay, M. R.; Siengchin, S.; Jawaid, Mand.; Parameswaranpillai, J. Characterization of raw and alkali treated new natural cellulosic fibers from Tridax procumbens. International Journal of Biological Macromolecules 2019, 125(15), 99-108.

[78] Zahari, W. Z. W.; Badri, R. N. R. L.; Ardyananta, H.; Kurniawan, D.; Nor, F. M. Mechanical properties and water absorption behavior of polypropylene/ljuk fiber composite by using silane treatment. Procedia Manufacturing 2015, 2(1), 573-578.

[79] Bezerra, A. F. C.; Carvalho, L. H.; Cavalcanti, W. S.; Barbosa, A. G. Mechanical behavior of composites reinforced with fibers caroa. Fibers and Polymers 2016, 17(1), 1908-1915.

[80] Karim, M. R. A.; Tahir, D.; Hussain, A.; Haq, E. U.; Khan, K. I. Sodium carbonate treatment of fibres to improve mechanical and water absorption characteristics of short bamboo natural fibres reinforced polyester composite. Plastics, Rubber and Composites 2020, 49(10), 425-433.

[81] Wang, X.; Guo, C.; Song, K. The effects of maleated polybutadiene-grafted polypropylene (MAPB-gPP) content on the properties of wood flour/polypropylene composites. Journal of Vinyl and Additive Technology 2020, 26(1), 17-23.

[82] Fonseca, J. S.; Martins, G. A. Curso de Estatística, 3rd ed.; Editora Atlas: São Paulo, Brazil, 1986, pp. 286.

\section{Figures}




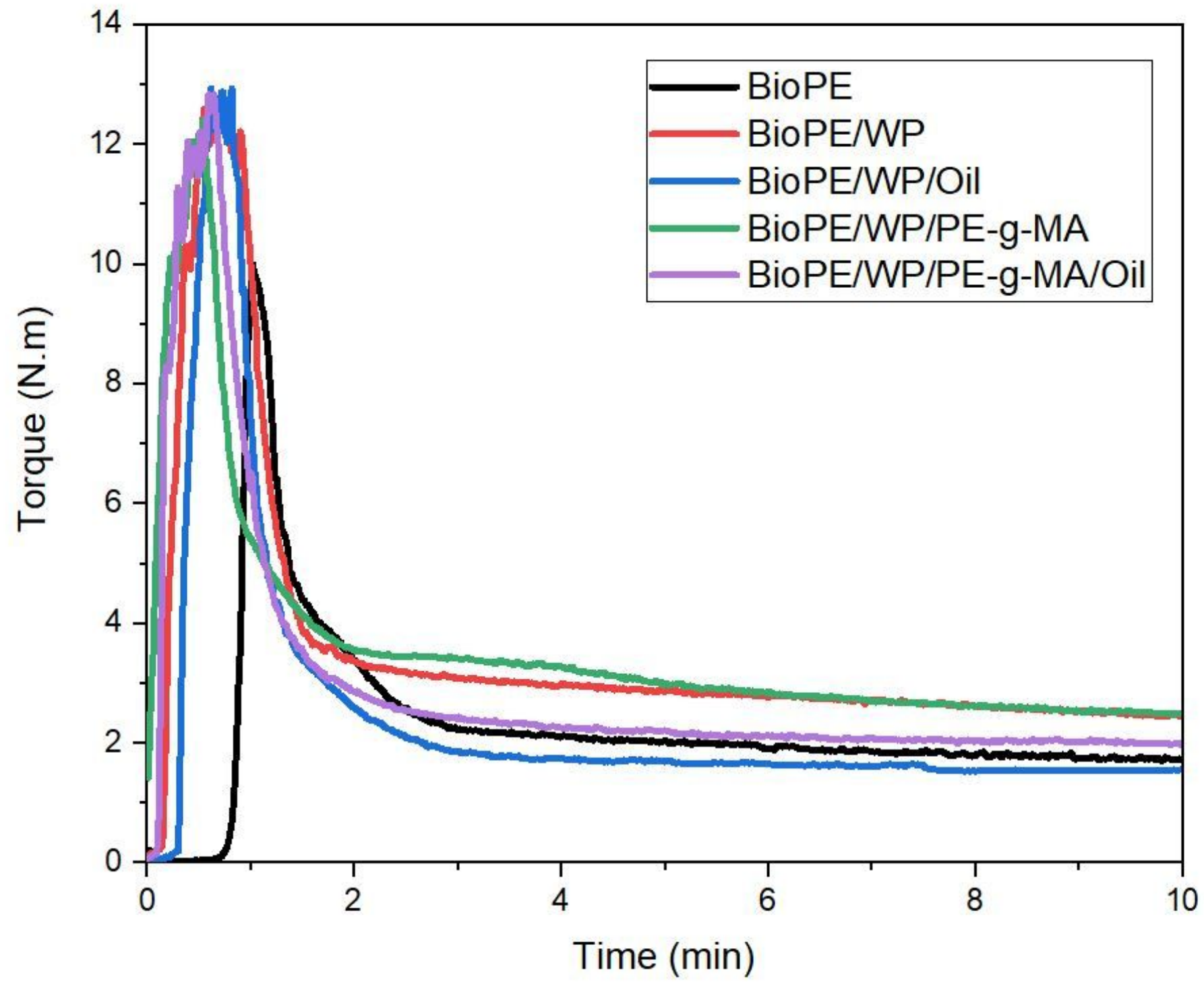

Figure 1

Torque versus time curves for neat BioPE and composites, with and without macaíba oil. 


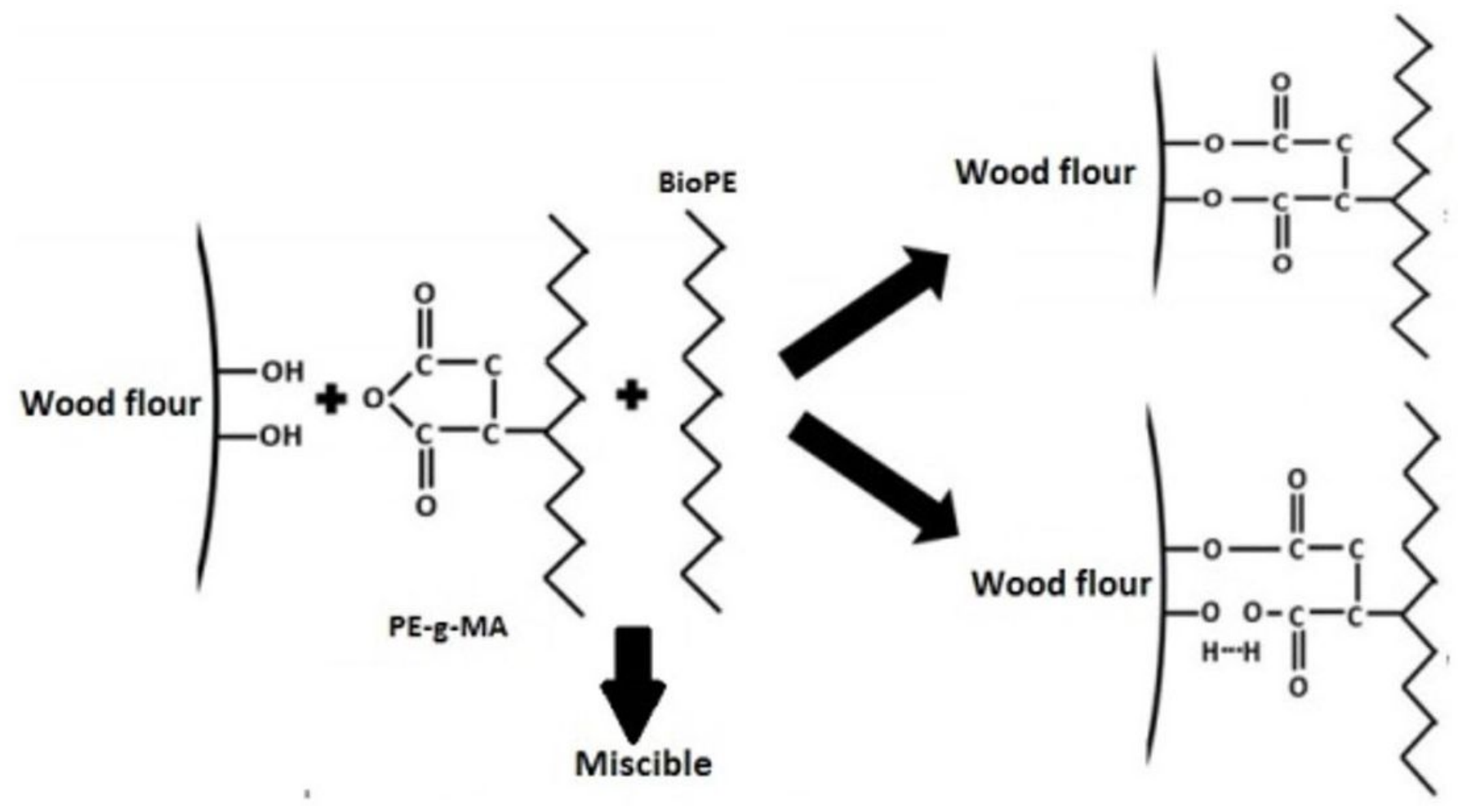

Figure 2

Proposed reaction for the compound BioPE/WP/PE-g-MA, with adaptation of [39]. 


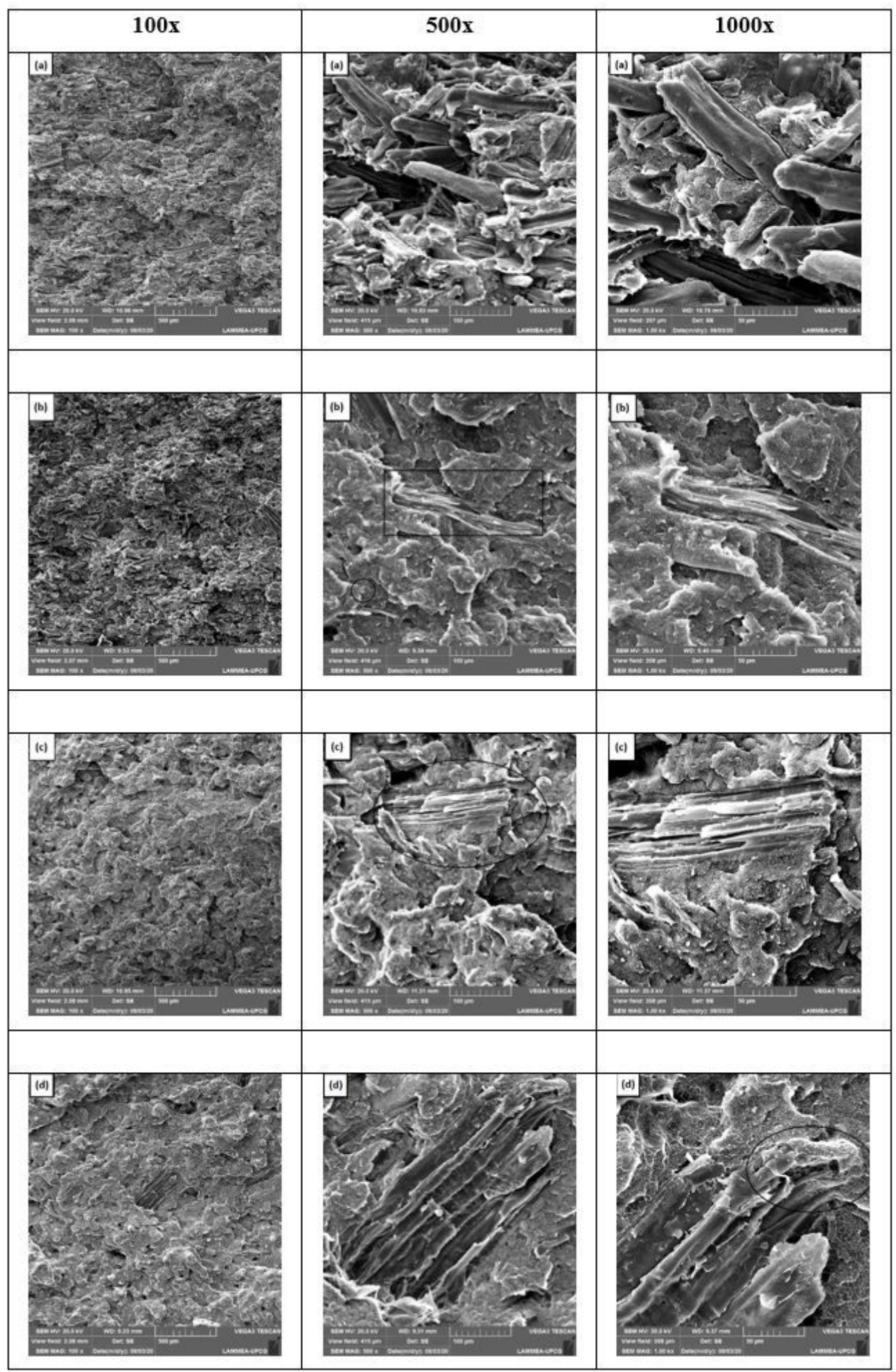

Figure 3

SEM images of the fractured surfaces, with 100x; 500x and 1000x magnification: (a) BioPE/WP; (b) BioPE/WP/oil; (c) BioPE/WP/PE-g-MA; (d) BioPE/WP/PE-g-MA/oil. 


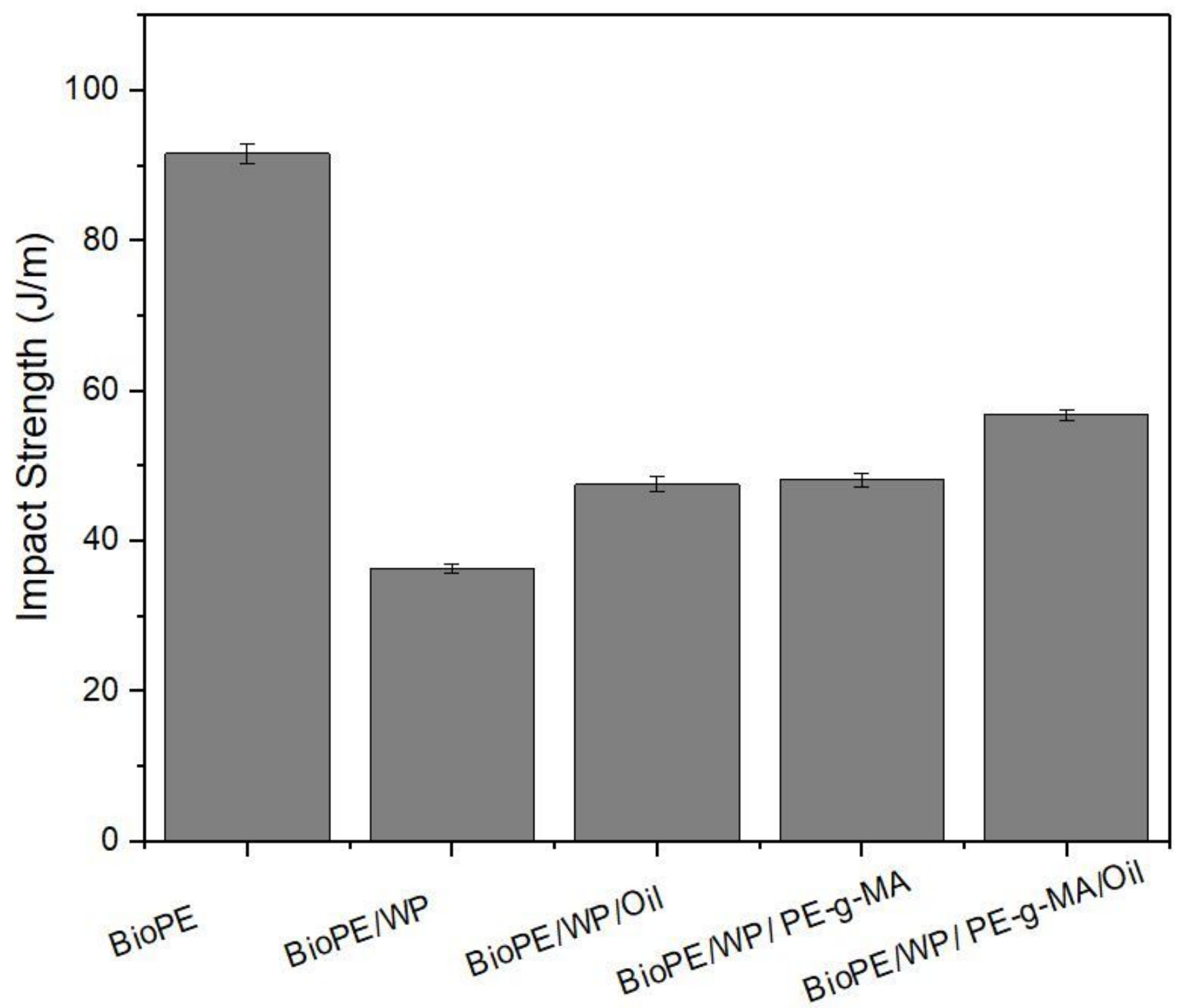

Figure 4

Izod impact strength of BioPE and composites, with and without macaiba oil.

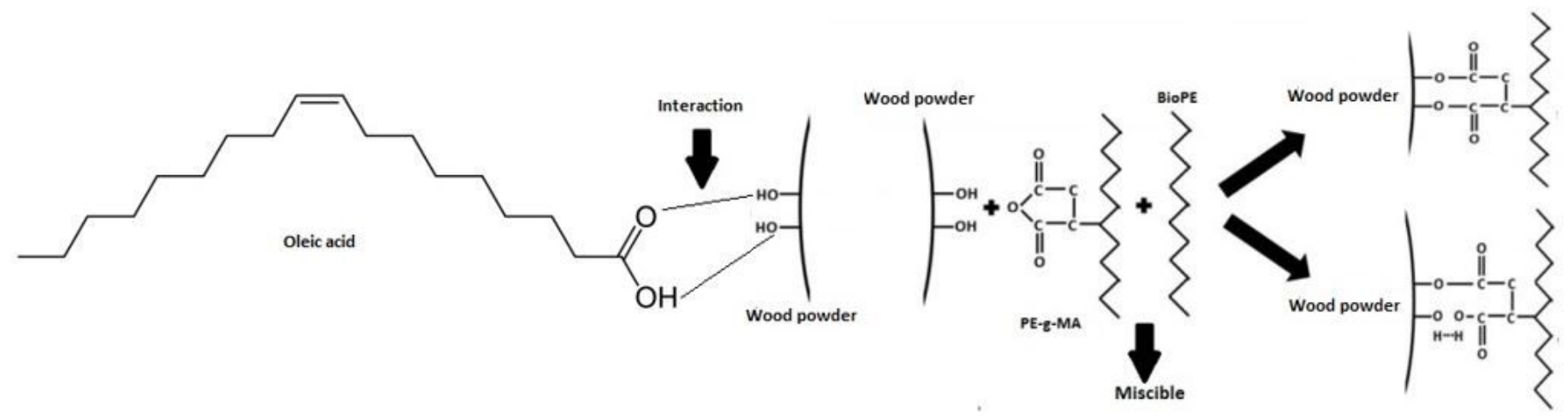

Figure 5 
Proposed reaction for the compound BioPE/WP/PE-g-MA/oil, with adaptation of [39].

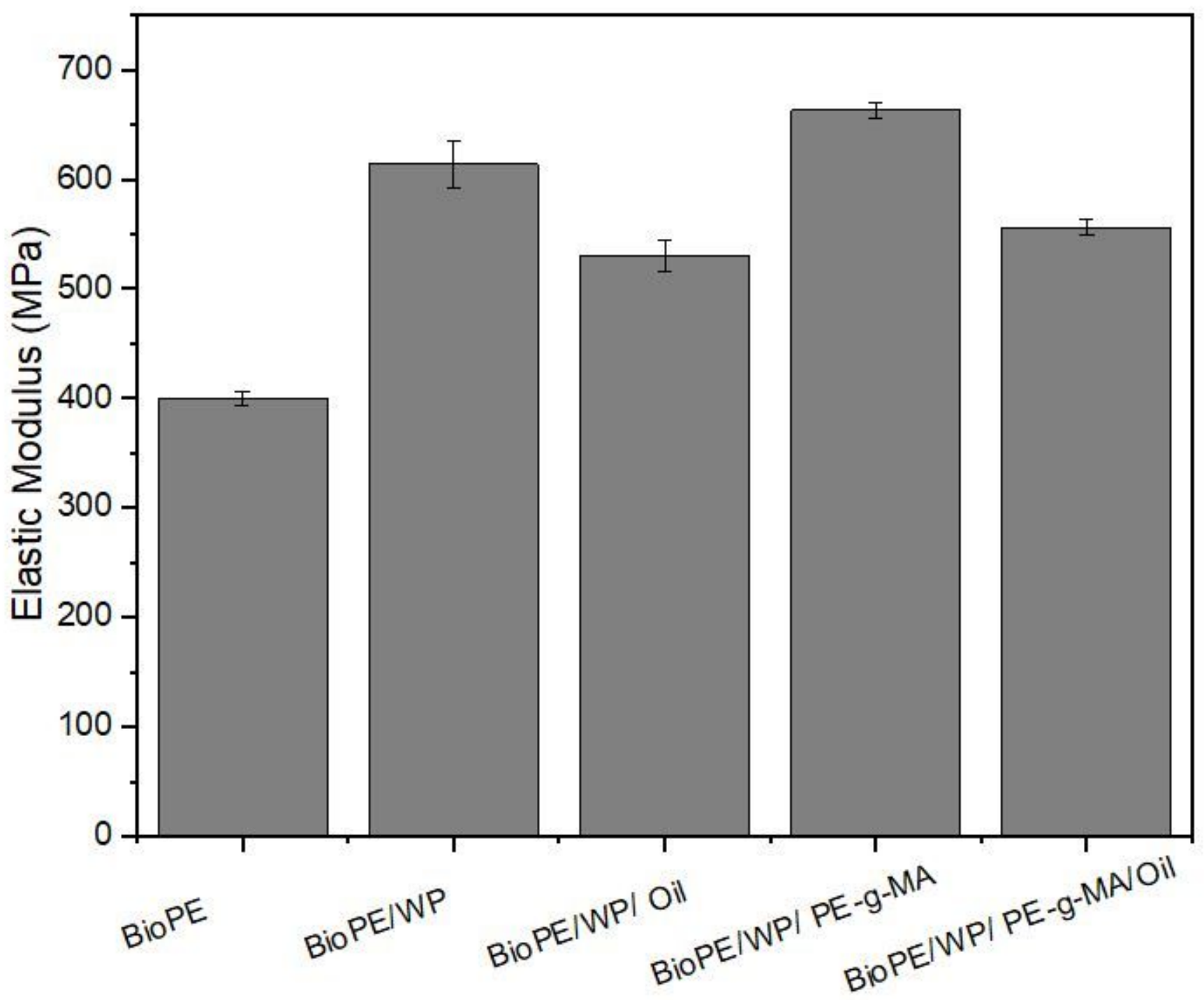

Figure 6

Elastic modulus of BioPE and composites, with and without macaíba oil. 


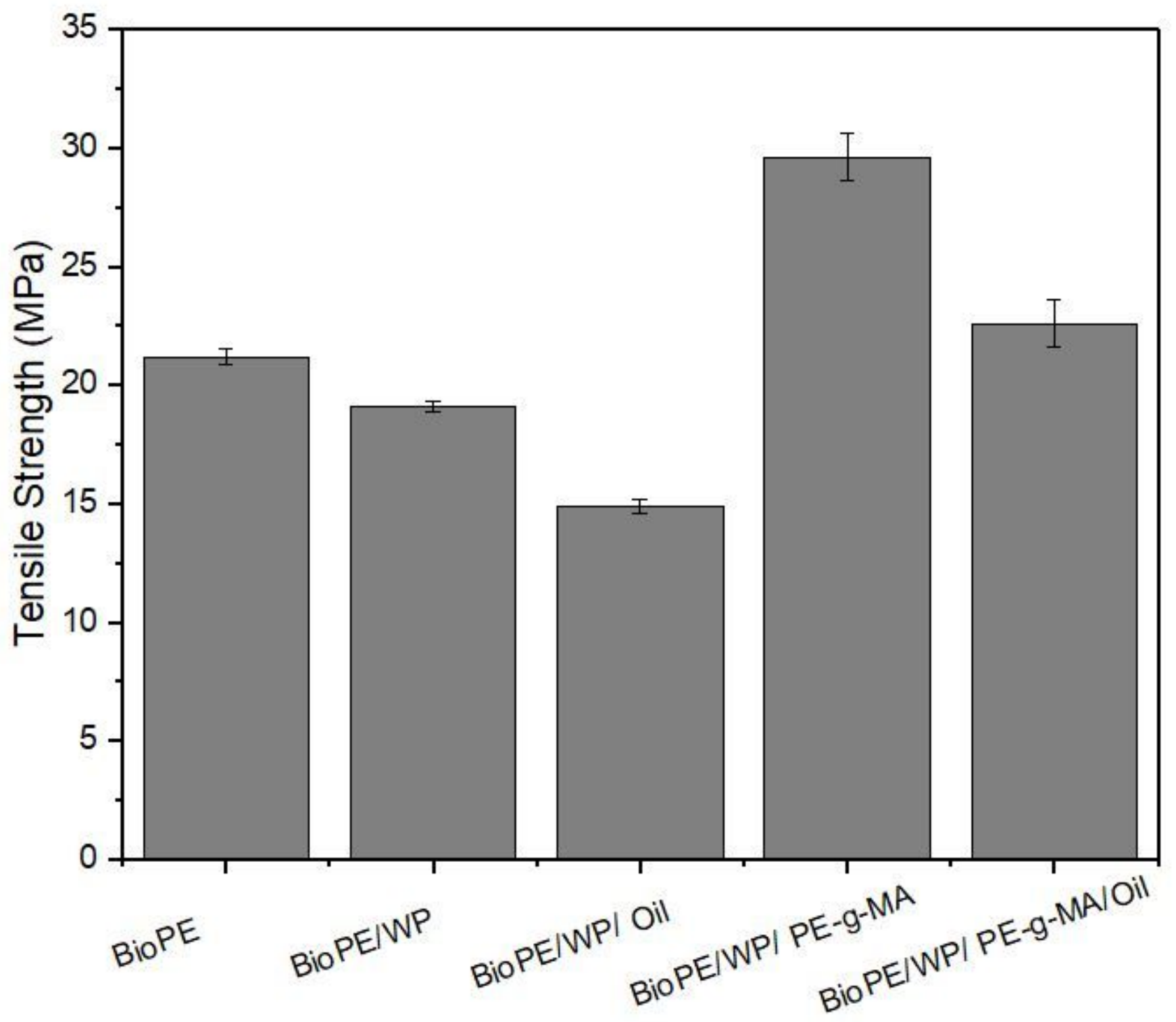

Figure 7

Tensile strength of BioPE and composites, with and without macaíba oil. 


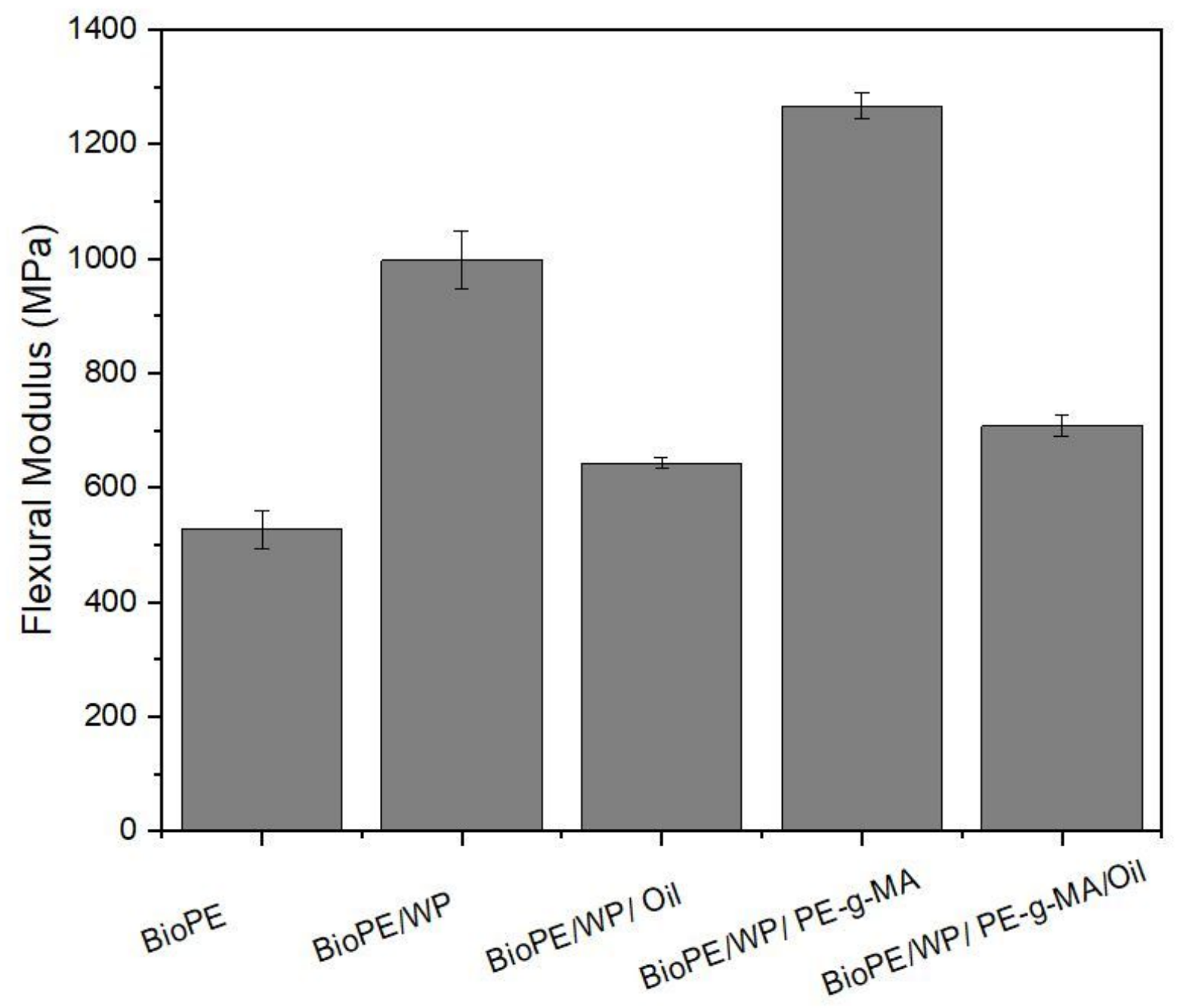

Figure 8

Flexural modulus of BioPE and composites, with and without macaíba oil. 


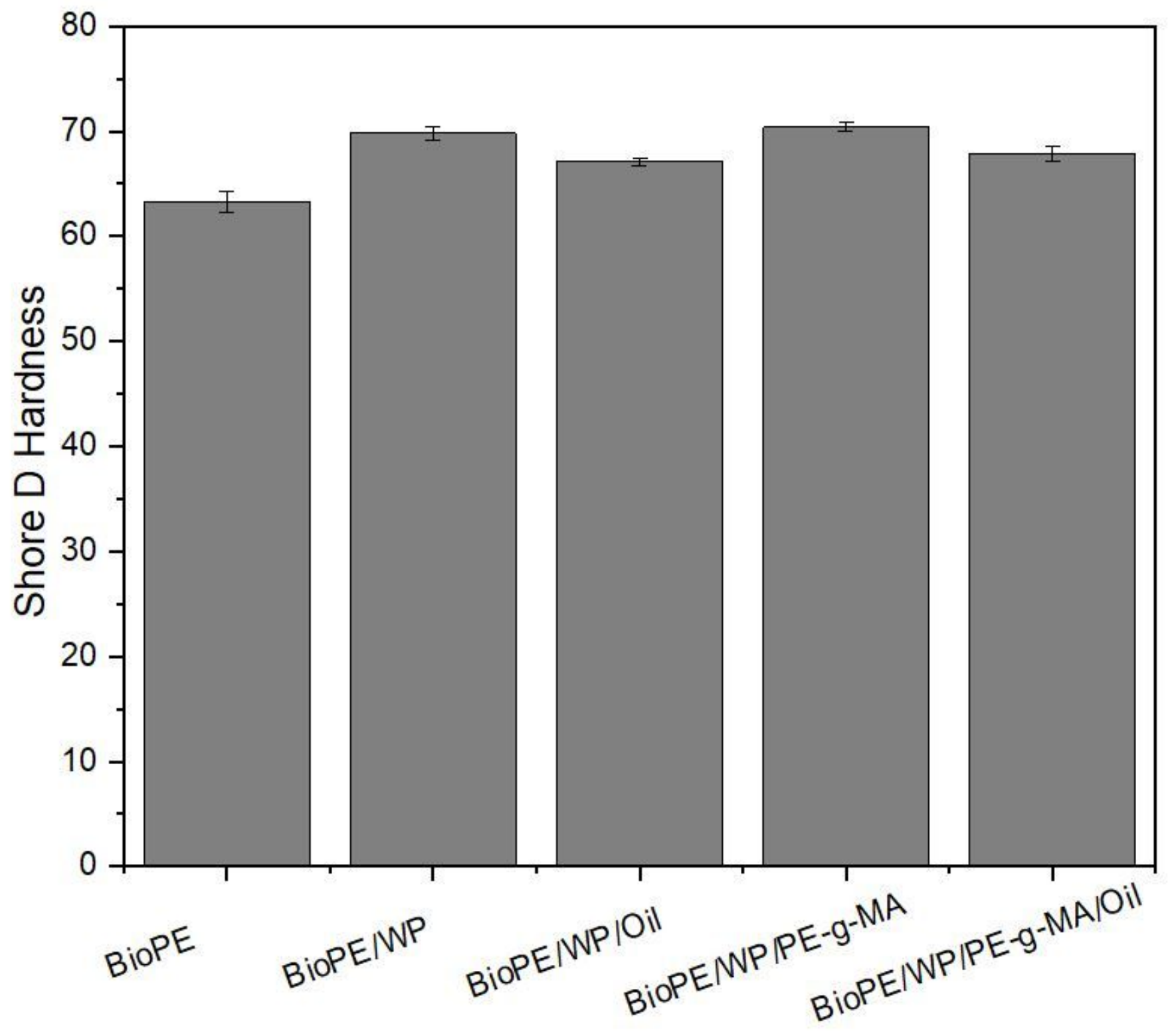

Figure 9

Shore D hardness of BioPE and composites, with and without macaiba oil. 


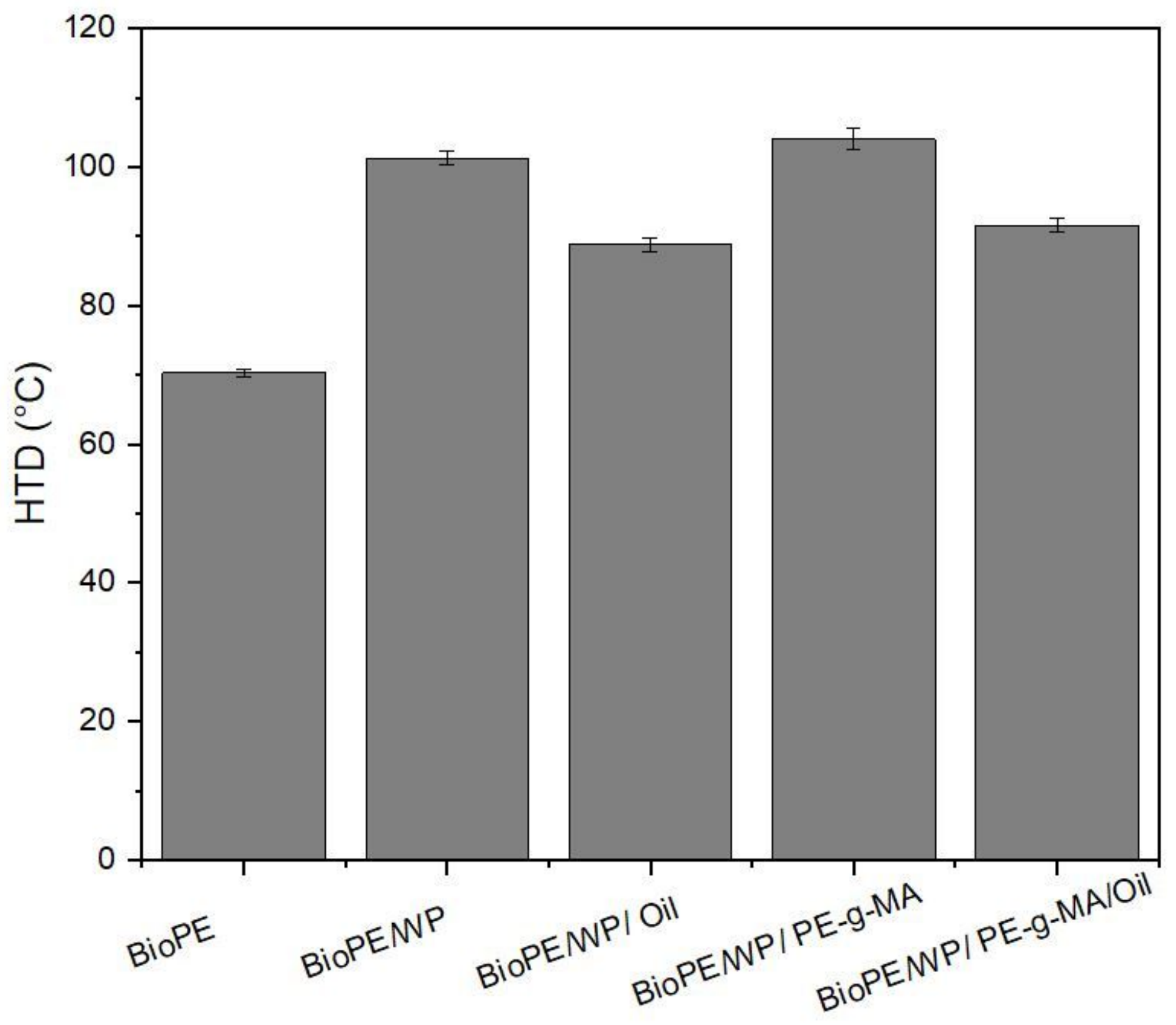

Figure 10

Heat deflection temperature of BioPE and composites, with and without macaíba oil. 


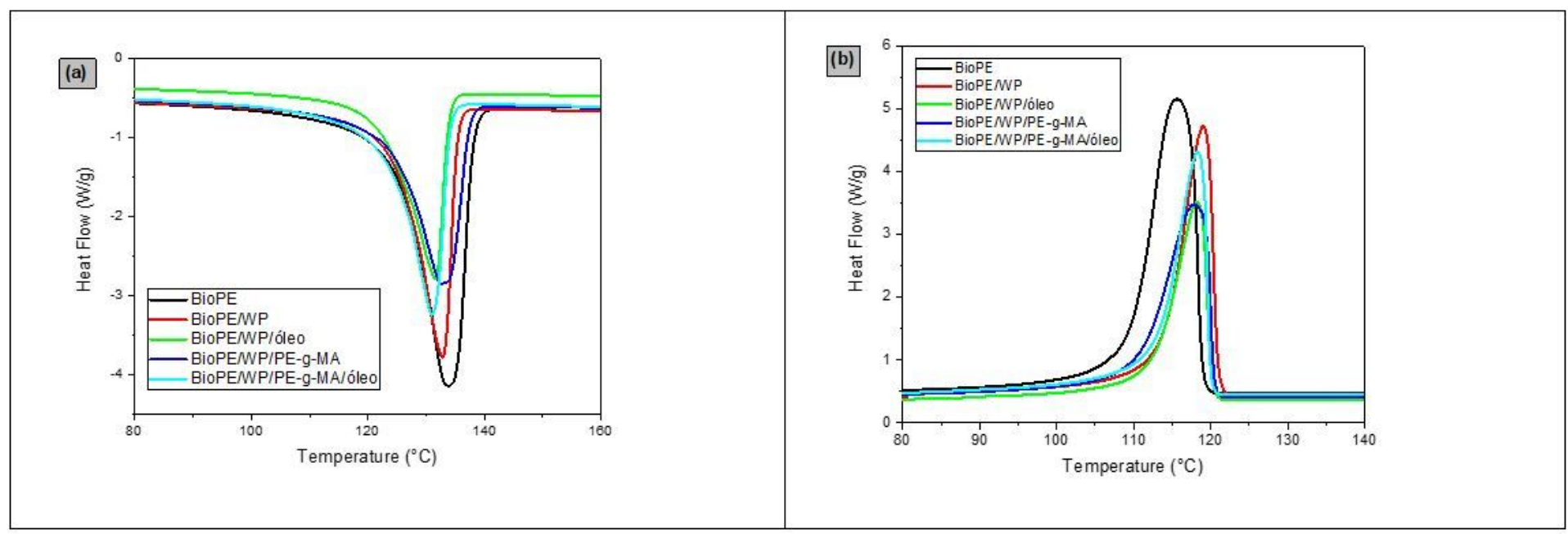

Figure 11

DSC curves for neat BioPE and composites: (a) melting temperature and (b) crystallization temperature.

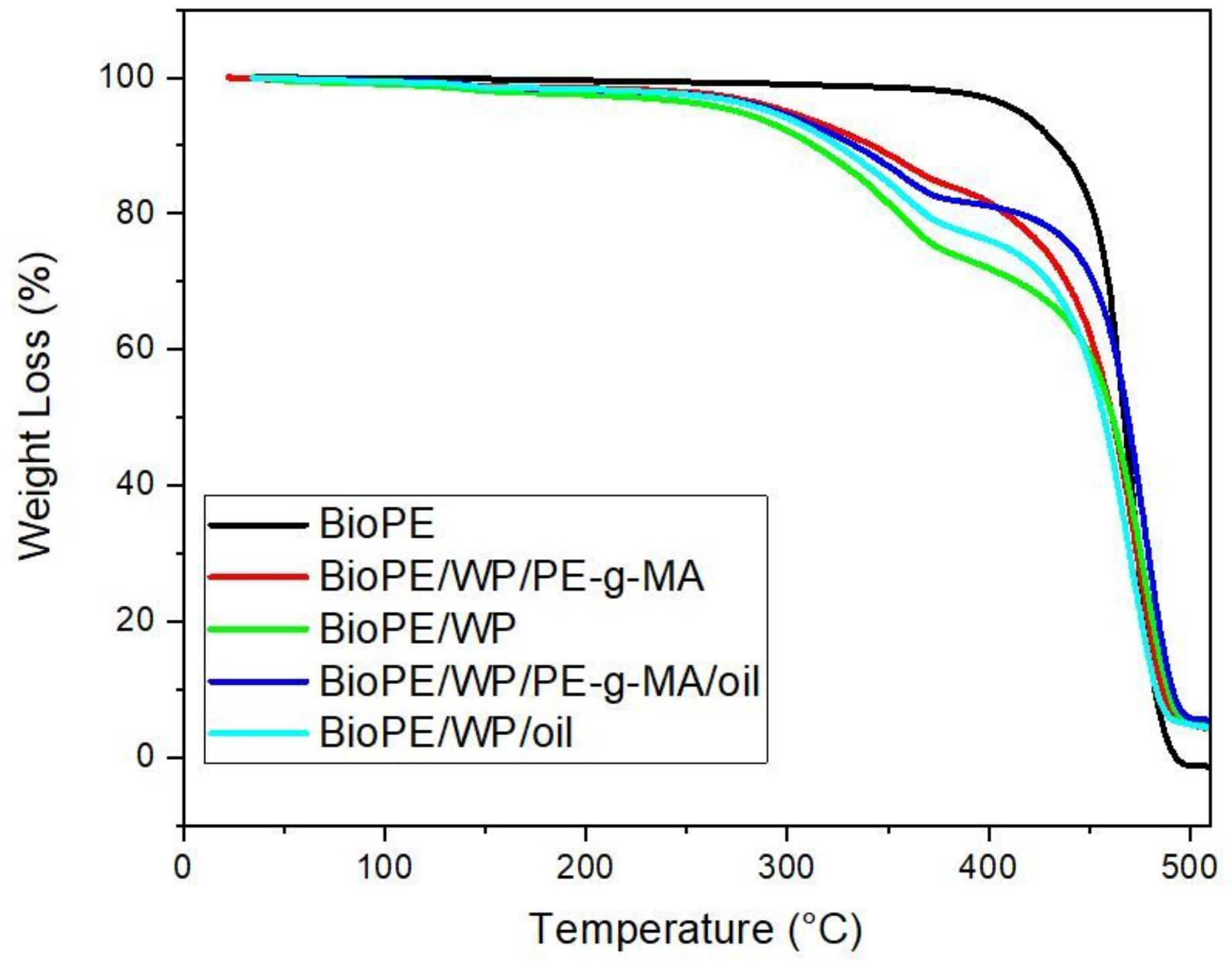


Figure 12

TG's curves of BioPE and composites, with and without macaíba oil, respectively.

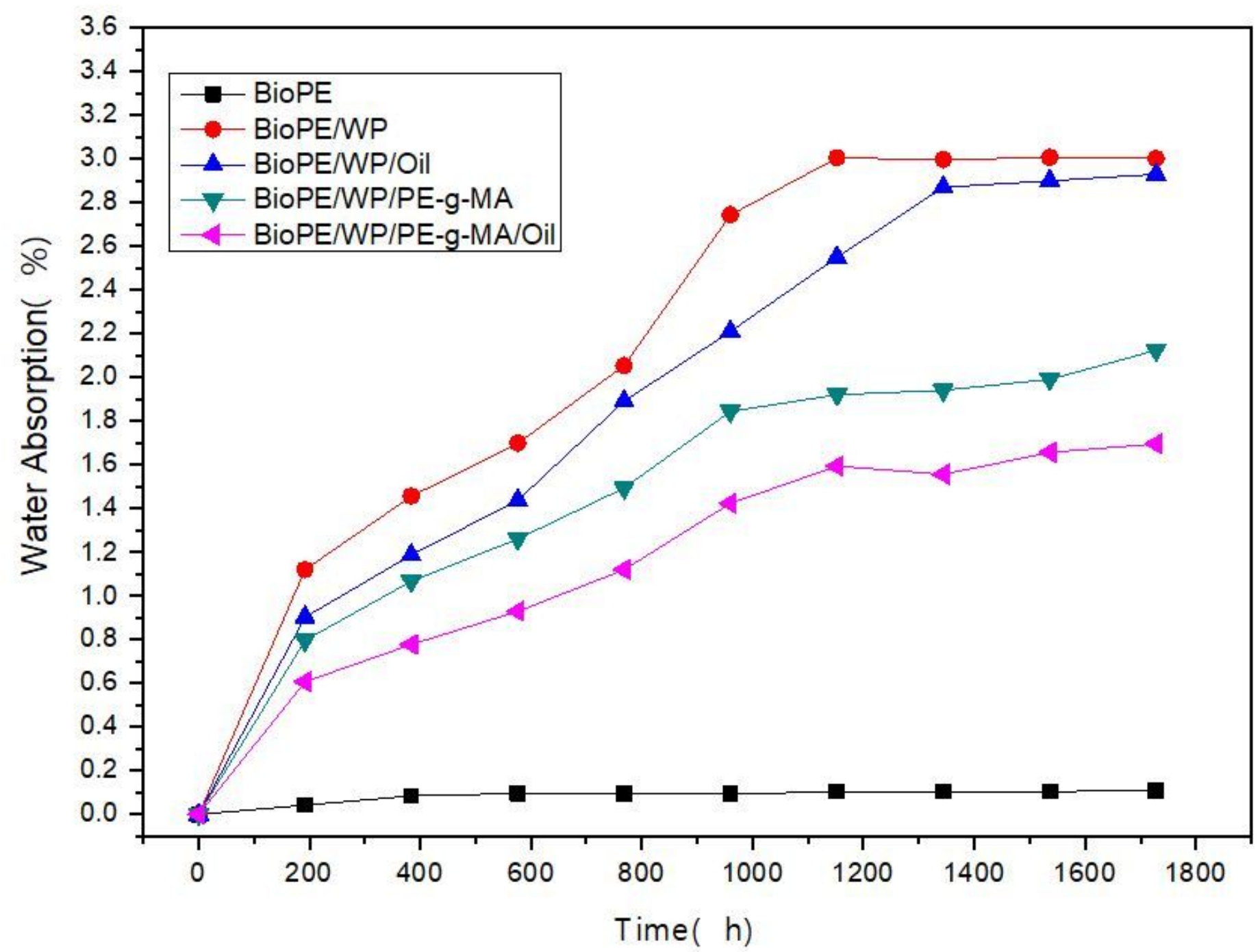

Figure 13

Water absorption of BioPE and composites, with and without macaíba oil, respectively. 